\title{
Forecasting Volatility in Taiwan with Encompassing Regression Models
}

\author{
Changwen Duan ${ }^{1}$, Ken Hung ${ }^{2}$, Shinhua Liu ${ }^{3, *}$ \\ ${ }^{1}$ Department of Banking and Finance, Tamkang University, New Taipei City, Republic of China \\ ${ }^{2}$ Sanchez School of Business, Texas A\&M International University, Laredo, United States \\ ${ }^{3}$ College of Business, University of Southern Mississippi, Hattiesburg, United States
}

Email address:

107800@mail.tku.edu.tw (Changwen Duan),Shinhua.liu@usm.com (Shinhua Liu)

${ }^{*}$ Corresponding author

To cite this article:

Changwen Duan, Ken Hung, Shinhua Liu. Forecasting Volatility in Taiwan with Encompassing Regression Models. International Journal of Economics, Finance and Management Sciences. Vol. 9, No. 2, 2021, pp. 62-76. doi: 10.11648/j.ijefm.20210902.12

Received: December 24, 2020; Accepted: January 8, 2021; Published: April 23, 2021

\begin{abstract}
Volatility forecasting is important both theoretically and in practice, varying by forecasting methods and financial markets. In this article, we explore this topic in the Taiwanese markets, using the encompassing regression models. We use the volatility of the Taiwan Stock Index (TAIEX) and its futures in the encompassing regression model to respectively make asynchronous forecasts of realized volatility (RV) and implied volatility (IV). Besides trading frequency, we find that transaction matching time is a key factor for obtaining steady RV values. Also, we find that the TAIEX index RV has a long memory. Moreover, we discover that, to obtain a stationary RV with a stable, long memory parameter, the optimal sampling intervals for the intraday return were nine (9) and thirty (30) minutes. In addition, we uncover that the spot volatility is more predictive of RV than the futures volatility. In the forecasting of IV, the volatility of futures has more information content, which can help improve overall forecast performance, especially when employing the ARFIMA+Jump model in the non-bear market and the ARFIMA+Jump/Leverage model in the bear market. The empirical result implies that the underlying asset of the TAIEX options (TXO) is approximately the index futures rather than the spot index, owing mainly to the demands for hedging and arbitrage from the TXO holders.
\end{abstract}

Keywords: Bayesian ARFIMA, Encompassing Regression, Forecasting, Implied Volatility, Realized Volatility, Taiwan

\section{Introduction}

There has been sustained interest in volatility forecasting in the finance literature, as illustrated by some recent studies [7, $40,50]$. The literature on volatility forecasting can be roughly grouped into two branches, one about realized volatility (RV) and another about implied volatility (IV). Realized volatility forecasting is conducted through historical volatility (HV) and implied volatility, such as those studies carried out by Canina and Figlewski, Christensen and Prabhala, and Jiang and Tian $[13,19,33]$. These studies maintain that IV or perhaps HV could be an unbiased estimator of RV under the efficient-market hypothesis and can be used as the predictor variable for RV. Canina and Figlewski and Christensen and Prabhala find that implied volatility has virtually no correlation with future return volatility and does not appear to incorporate information contained in historical return volatility [13, 19]. However, Jiang and Tian [33] provide support for the informational efficiency of the option markets.

Implied volatility forecasting is accomplished through the RV, HV or IV for at-the-money options, as done by Chan, Jha, and Kalimipalli [15]. The main contribution of above studies is that those models can forecast IV in real investment simulations. They compare real investment performance of different forecasting models. However, they do not compare the information content of volatility in the spot market with that in the futures market in the same time period. The current study intends to fill this void.

According to the efficient-market hypothesis, futures price should lead spot price when new information arrives, because futures market provides a function of price discovery. Empirically, many studies have documented that futures market incorporates new information more efficiently than spot market and, thus, futures returns overall tend to lead more often than lag spot index returns. For example, Kawaller, 
Koch, and Koch find that the S\&P 500 index futures lead spot index by about 45 minutes [35]. Stoll and Whaley also discover that return on S\&P 500 and MMI index futures lead spot by about 5 minutes [49]. Chan and Fleming, Ostdiek and Whaley report similar findings [14, 24].

In Taiwan the first TAIEX (Taiwan Stock Exchange Capitalization Weighted Stock Index Taiwan stock index) futures contract was launched by Taiwan Futures Exchange (TAIFEX) on July 21, 1998. The empirical studies about price relationship between spot and futures prices on TAIEX are mixed. Some of the evidence indicates that price discovery is still dominated by cash market while other evidence shows that the returns of TAIEX futures lead those of cash market. For example, Lin, Chen, Hwang and Lin investigate the interaction of return and volatility between the TAIEX futures and the TAIEX spot markets [39]. They found that the price discovery process is dominated by the TAIEX spot market in terms of return and volatility. Hsieh investigates information transmission [29] between the TAIEX futures and the underlying spot index in terms of return. He finds that futures market dominants the spot market in price discovery. Jang and He, employing a regression model, investigate the intraday price relationships between the spot, futures and options markets for the TAIEX [32]. They find that the TAIEX futures returns lead the TAIEX returns by about 20 minutes. Overall, index futures tend to lead more often than lag the cash index in price discovery.

It seems that much of the literature does not discuss the leading effect of volatility with information content in futures market. If futures volatility with superior information leads spot volatility, futures volatility should possess superior forecasting ability than spot volatility, due mainly to the price discovery function in the futures market. In this paper, the TAIEX, the TAIEX futures (TX), and the TAIEX options (TXO) are used to calculate different volatilities to be incorporated into the encompassing regression model to forecast the RV and IV. Such an approach could contribute to the literature by comparing the information content of cash-based volatility with that of futures-based volatility.

Such an effort is interesting for a number of reasons. First, futures volatility is added as a predictor variable with incremental information to forecast IV. Second, forecast values are used for all predictor variables in the encompassing model to generate an asynchronous regression model so that the model would be realistic enough to be close to the real world. Finally, a simulation of the multiple of the smallest matching time for transaction is conducted to obtain stable intra-day data for RV calculation by using long-memory parameter and coefficient values synchronously estimated by Bayesian ARFIMA approach., which could reduce the bias created by the two-step maximum likelihood estimate (MLE) method.

We decide to adopt the encompassing regression model in light of the evolving literature. Many studies that examine volatility models have cited the methods and results of Lamoureux and Lastrapes, who tracked 10 individual stock options to test several volatility models, as a benchmark for comparison in order to verify the accuracy of their empirical results [38]. They criticize that their option data is outdated, their sample size is insufficient, and their methodology is incomplete. These deficiencies are responsible for the bias and inefficiency of the empirical results of Lamoureux and Lastrapes [38]. Canina and Figlewski find that the IV from the S\&P100 index options is a poor forecast for the subsequent $\mathrm{RV}$ of the underlying index [13]. They apply an encompassing regression analysis and find that IV has virtually no correlation with future RV and thus does not incorporate information contained in historical volatility.

Likewise, our use of options data follows the literature. However, according to Rubinstein, the US option market has undergone a structural change since 1987 [47]. He contends that only high liquidity options possess valuable information. Several related studies consistently discover that the implied volatility of high liquidity options has better information content. Mayhew suggests using nearly at-the-money option to estimate implied volatility for pricing option with identical maturity [41]. The empirical method shows that the at-the-money implied volatility is an important variable. After reviewing 93 papers on volatility, Poon and Granger conclude that implied volatility with more relevant information has the best forecasting ability and high-liquidity at-the-money option has the least error [45]. Accordingly, our research sample comprises of only nearly at-the-money option contracts.

Our empirical results and findings are as follows. Trading frequency and transaction matching time are conducive to a stable RV. The multiple of 45 seconds $(6,9,15$, and 30 minutes) transaction matching time helps calculating Taiwan stock index RV with stability. We observe a stable long memory parameter in 9 and 30-minutes RV values. Spot HV has higher RV forecasting ability than futures HV. Furthermore, we find that futures volatility has higher forecasting ability for IV. Therefore, the futures market leads the spot market in Taiwan. Our empirical results imply that the underlying asset for implied TXO is approximately TX, not TAIEX. It is due to the hedging and arbitraging needs from option holders. Finally, through trading simulations of a delta-neutral straddle portfolio using various IV forecasts, we observe not only long memory but also jump tendency in the return of TAIEX.

The remainder of the paper is organized as follows. Section 2 describes data and methodology. Section 3 introduces the estimation methods of volatility forecasts. Section 4 discusses the main results and checks their robustness. Section 5 concludes.

\section{Data and Methodology}

\subsection{Data}

Our samples include Taiwan Stock Exchange Capitalization Weighted Stock Index (TAIEX), TAIEX futures (TX) and TAIEX options (TXO) traded on the Taiwan security market over the period December 24, 2001 to May 20, 2008. The daily and intraday data are provided by Taiwan Economic Journal (TEJ) database, TAIFEX and TWSE (Taiwan Stock Exchange). We restrict our data to pre-May 20, 2008 as TAIEX plunged significantly after the Presidential election. During the months after the Presidential election, the stock market collapsed on May 21, 2008. To test the effectiveness of the forecasting 
models, we use an out-of-sample period from December 19, 2007 to May 20, 2008. Figure 1 presents TAIEX and its return during the sample period. The patterns of TAIEX in Figure 1 (period before the vertical dashed line) shows that our sample period contains both bull and bear markets. Furthermore, the pattern (period after the vertical dashed line) of TAIEX shows a sharp decrease following the Presidential election. As such, we use another post-election out-of-sample period, May 21, 2008 to October 9, 2008, for robustness test.

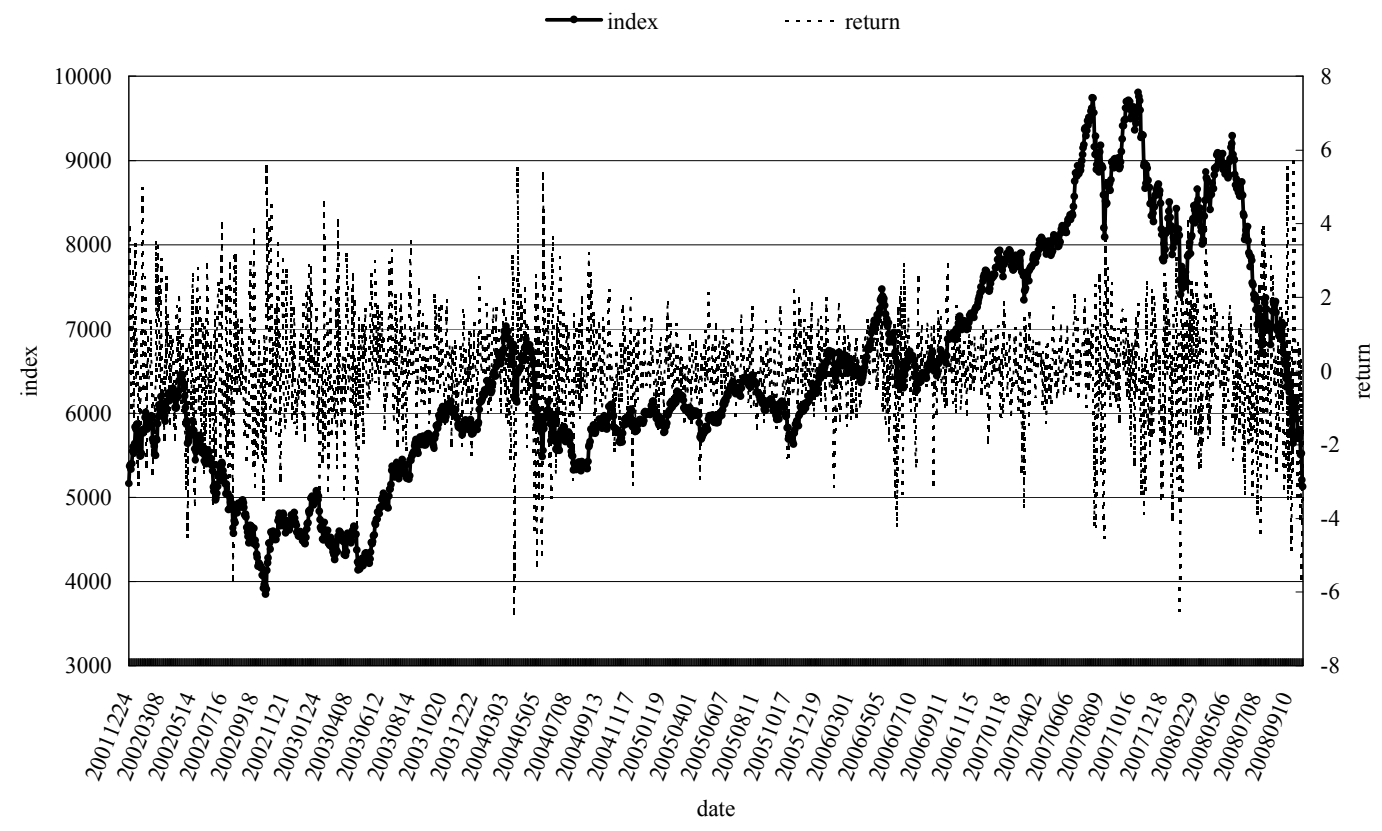

Note: The post-Presidential election period is after the vertical dashed line.

Figure 1. Index level and return of TAIEX from December 24, 2001 to October 9, 2008.

We use nearby contracts owing to the low turnover of the distant contracts. Additionally, many prior studies suggest that the last few days before the expiration of the futures contracts reveal unusual trading activities and higher volatility. Contracts are thus rolled over to the next nearby contract on the 7 th day before expiration to mitigate the expiration effects. Thus, our samples of futures and options contracts will be nearby contracts with a maturity period of 8 to 30 days. In addition, if the implied volatility is negative or greater than $100 \%$, the contract is eliminated. Finally, we proxy for the risk-free interest rate using 1-month time deposit rate from the First Bank of Taiwan.

The stocks are traded on the Taiwan Stock Exchange during trading hours from 9:00 am to 1:30 pm, Monday to Friday. However, the trading hours for the TAIEX futures and options extend from 8:45 am to 1:45 pm. We thus truncate the first and last 15 minutes of the data on futures trading to match the trading hours for the futures and stocks.

We compute moneyness following Bakshi, Cao, and Chen [8]. Owing to the non-tradability of the TAIEX and the non-synchronous problems, we employ the TAIEX futures index in computing moneyness $(\mathrm{M})$ :

$$
\text { Moneyness }=\frac{T X}{K}
$$

where TX is daily closing price with a nearby contract (if no closing price on the day, we replace the closing price with settlement price), $\mathrm{K}$ is the strike price. Contracts with an absolute value of $\mathrm{M}$ from 0.97 to 1.03 are the placed into the at-the-money (ATM) categories. Options with absolute moneyness below 0.02 or above 0.98 are excluded due to the distortion caused by price discreteness.

\subsection{Models}

Studies on volatility relationships have generally emerged from the perception that estimated volatility is an informationally efficient predictor. A particularly simple and intuitive approach for testing this conjecture is to run the Mincer and Zarnowitz predictive regressions [42]. This methodology is still by far the dominant approach in the literature addressing the efficiency and bias issue of volatility forecasts. The setting for Mincer and Zarnowitz's model accommodates traditional univariate predictive regressions as well as extended encompassing regressions [42]. The generic notation for the regressor and regressands emphasizes the fact that the exposition applies across alternative transformations of volatility measures and forecasts, such as basic variances, standard deviations or volatilities and log-volatilities, which each may have desirable empirical or theoretical properties.

The encompassing regression analysis can well explain dependent variables from the information content contained in independent variables. In a study of the forecasting ability of volatility models, it is quite obvious that selecting independent variables with strong forecasting ability is an important task. Clemen points out that a mixture of at least two types of volatility forecasts can have better forecasting performance for RV than a single type of volatility [20]. Following prior research (e.g., 
Canina and Figlewski, and Christensen and Prabhala,), we employ encompassing regressions to examine the ability to forecast RV and IV $[13,19]$. In encompassing regression model, realized and implied volatilities are regressed against three volatility forecasts respectively in order to distinguish which one has the highest explanatory power. ${ }^{1}$ In addition, the information contents of spot volatility and futures volatility are compared.

Dumas, Fleming, and Whaley utilize deterministic volatility function (DVF) to estimate the relationship of implied volatility and five endogenous variables [21]. The model has a very high explanatory power implying that the volatility formed by DVF has indeed incremental information. In view of the criticism raised by Lamoureux and Lastrapes and Canina and Figlewski with regards to the informational superiority of IV, we extend the model to include the DVF implied volatility (DVFIV) [38, 13].

First, we combine HV, IV, and DVFIV as three proxy volatility variables to forecast $\mathrm{RV},\left(\sigma_{\mathrm{t}}^{\mathrm{RV}}\right)$, the realized volatility. The model (RV model) is expressed as follows:

$$
\begin{aligned}
\operatorname{Ln}\left(\sigma_{t}^{\mathrm{RV}}\right)= & \beta_{0}+\beta_{1} \operatorname{Ln}\left(\sigma_{\mathrm{t} \mid \Omega_{\mathrm{t}-1}}^{\mathrm{HV}}\right)+\beta_{2} \operatorname{Ln}\left(\sigma_{\mathrm{t} \mid \Omega_{\mathrm{t}-1}}^{\mathrm{IV}^{\mathrm{e}} \mathrm{ATM}^{\mathrm{e}}}\right) \\
& +\beta_{3} \operatorname{Ln}\left(\sigma_{\mathrm{t} \mid \Omega_{\mathrm{t}-1}}^{\mathrm{DVFIV}^{\mathrm{e}}}\right)+\varepsilon_{\mathrm{t}}
\end{aligned}
$$

where $\beta$ 's and $\varepsilon$ are respectively the regression coefficients and error term, $\sigma_{\mathrm{t} \mid \Omega_{\mathrm{t}-1}}^{\mathrm{HV}^{\mathrm{e}}}, \quad \sigma_{\mathrm{t} \mid \Omega_{\mathrm{t}-1}}^{\text {IVATM }^{\mathrm{e}}}$ and $\sigma_{\mathrm{t} \mid \Omega_{\mathrm{t}-1}}^{\text {DVFIV }^{\mathrm{e}}}$ are respectively the day-t predictors of historical volatility (HV), ATM implied volatility (IV) and implied volatility computed by the deterministic volatility models (DVFIV), conditional on information at day $\mathrm{t}-1$. The superscript e stands for expected value. Equation (2) contains multiple forecasts and is, thus, often called an "encompassing regression". We use both spot index and index futures separately to estimate historical volatility and to ascertain that both HV estimates could be unbiased estimators of RV. Furthermore, we forecast IV using HV and RV obtained from spot index and index futures. Thus, we set up the following encompassing regression (IV-RV) model:

$$
\begin{aligned}
& \operatorname{Ln}\left(\sigma_{t}^{\mathrm{IV}}\right)=\beta_{0}+\beta_{1} \operatorname{Ln}\left(\sigma_{\mathrm{t} \mid \Omega_{\mathrm{t}-1}}^{\mathrm{TX}-\mathrm{HV}^{\mathrm{e}}}\right)+\beta_{2} \operatorname{Ln}\left(\sigma_{\mathrm{t} \mid \Omega_{\mathrm{t}-1}}^{\mathrm{TX}-\mathrm{RV}^{\mathrm{e}}}\right) \\
& +\beta_{3} \operatorname{Ln}\left(\sigma_{\mathrm{t} \mid \Omega_{\mathrm{t}-1}}^{\mathrm{TXF}-H V^{\mathrm{e}}}\right)+\beta_{4} \operatorname{Ln}\left(\sigma_{\mathrm{t} \mid \Omega_{\mathrm{t}-1}}^{\mathrm{TXF}-\mathrm{RV} V^{\mathrm{e}}}\right)+\varepsilon_{\mathrm{t}}
\end{aligned}
$$

where $\sigma_{t}^{\mathrm{IV}}$ is implied volatility. $\sigma_{\mathrm{t}}^{\mathrm{TX}-\mathrm{HV}}$ and $\sigma_{\mathrm{t}}^{\mathrm{TX}-\mathrm{RV}}$ are respectively historical volatility and realized volatility of TAIEX. $\sigma_{\mathrm{t}}^{\mathrm{TX}-\mathrm{HV}}$ and $\sigma_{\mathrm{t}}^{\mathrm{TX}-\mathrm{RV}}$ are respectively historical volatility and realized volatility of TX. Following Christensen and Prabhala's hypotheses test in a univariate model, there are some hypotheses to be tested in our encompassing regression models [19]. The first is about the efficiency of the volatility

1 This is the main advantage of the model while a potential shortcoming is that when the number of independent variables increases, the model's testing power may decline.

2 This model is discussed in Fair and Shiller, and used by Lamoureux and Lastrapes, Jorion, Christensen and Prabhala, Campa and Chang, Jiang and Tian, etc. $[22,38,34,19,12,33]$. forecast. We test whether the volatility forecast subsumes all the information contained in realized or implied volatilities. In an affirmative case the slope coefficient of volatility forecast should be equal to zero. Moreover, as a joint test of information content and efficiency we test in equation (2) and (3) if the slope coefficients of all volatility are equal to zero and one respectively. Following Jiang and Tian, we ignore the intercept in the latter null hypothesis, and if our null hypothesis is verified, we interpret the volatility forecast as unbiased after a constant adjustment [33]. Differing from other papers that use spot and options to forecast volatility, we apply not only spot and option variables but also futures variable.

In our encompassing regression model, we expect to use spot volatility or futures volatility as an informational proxy variable to forecast IV. In the meantime, we could identify options traders' information source. The novelty vis-á-vis the previous literature is that forecasted values are used for explanatory variables in the encompassing regression model. Therefore, we have to forecast explanatory proxy variables before executing encompassing regressions.

The concept of forecasting realized and implied volatilities can be expressed as follows:

$$
\sigma_{t} \Leftarrow \hat{\sigma}_{t \mid \Omega_{t-1}}
$$

$\sigma_{\mathrm{t}}$ is the forecasted volatility at time $\mathrm{t}$, and $\hat{\sigma}_{t \mid \Omega}$ is the volatility forecasted at time $t$ using all information $(\Omega)$ collected at time $\mathrm{t}-1$. Our volatility forecasts will include information content coming from one-day-ahead (t-1), five-day-ahead (t-5) and 20-day-ahead (t-20). We then average across these estimated volatilities to obtain the volatility forecasts at time $t$.

Encompassing regression tests need to address several methodological issues such as possible measurement errors, telescoping errors, orthogonal errors, and biases (Fleming, Christensen and Prabhala, and Neely) [23, 19, 43]. Because our samples come from higher liquidity nearby futures and options contracts, the measurement errors should be low. Moreover, we estimate the coefficient of the encompassing regressions using the generalized method of moments (GMM) approach, which can minimize potential telescoping overlapping data problems. At the same time, any remaining measurement errors could lead to a descending bias in the encompassing regression.

Following many prior studies on volatility forecasts, we employ the following three metrics to compare the pricing performance of alternative volatility models: MSE (mean squared error), MAE (mean absolute error) and MAPE (mean absolute percentage error).

\subsection{Trading Strategies and Simulation}

Since the TAIEX is a non-traded asset, we use out-of-sample data to simulate pricing error for the value of forecasted IV in order to compare the forecasting ability of IV forecast model. Therefore, we use Equation (3) as the forecasting model. Furthermore, a trading strategy using options in portfolio could be formulated. Then we could observe whether the volatility forecast model could profit from abnormal returns. We use competing out-of-sample volatility forecasts to trade in nearly 
at-the-money delta-neutral straddles. In a trading rule, the theoretical strike price in a delta-neutral straddle can be solved as $N\left(d_{1}\right)+\left[N\left(d_{1}\right)-1\right]$. Furthermore, we determine that traded straddle combination whose strike price is closest to the theoretical strike price. Therefore, we form delta neutral ATM straddles each day in out-of-sample period, price them based on alternate volatility forecasts and then buy (sell) them on each day depending on whether they are underpriced (overpriced). When the straddle is a long (short) position, we assume that we can borrow (lend) funds at a risk-free rate. We apply the bid-ask spread as a filter for all the trades. Then we trade only when the absolute-value difference between the model and market price exceeds the average bid-ask spread on day t-1. Moreover, we also apply NT $\$ 80 /$ contract trading $\operatorname{cost}^{3}$. In measuring the risk-return tradeoff for option trading, we only consider robust Sharpe ratios, taking into account the underlying non-normal distributions.

\section{Estimation Methods of Volatility Forecasts}

\subsection{Historical Volatility $\left(\sigma^{H V}\right)$}

To estimate historical volatility, we apply the well-known formula of Parkinson (1980) to daily high and low stock prices as follows:

$$
\sigma_{t}^{H V}=\sqrt{\frac{1}{n} \sum_{t=1}^{n} \frac{1}{4 \operatorname{Ln}(2)}\left[\operatorname{Ln}\left(\frac{H_{t}}{L_{t}}\right)\right]^{2}} \times \sqrt{d a y}
$$

where $H_{t}$ and $L_{t}$ are the highest and lowest index level for day t, respectively. The $n$ and day are the number of observed days and business days, respectively. Following Gemmill and Chiras and Manaster, we take the historical 20-trading-day average as the historical volatility to mitigate the estimation noise $[25,16]$.

According to the prior literature on volatility forecast, HV has rather poor forecasting ability. To enhance the ability of $\mathrm{HV}$ forecasts, we compute the predictor of historical volatility using the ARMA (p, q) model, as defined below:

$$
\phi_{p}(B)\left(Z_{t}-\mu\right)=\theta_{q}(B) a_{t}
$$

where

$$
\phi_{p}(B)=1-\phi_{1} B-\cdots-\phi_{p} B^{p}
$$

$\theta_{q}(B)=1-\theta_{1} B-\cdots-\theta_{q} B^{q}$,

$B$ is backward shift operator. The $\mathrm{p}$ and $\mathrm{q}$ order of ARMA model can be determined by sample autocorrelation function (ACF), sample partial autocorrelation function (PACF) and sample extended autocorrelation function (EACF). Furthermore, we can obtain the predictor of HV forecasts by the property ARMA model.

\subsection{Implied Volatility $\left(\sigma^{I V}\right)$}

3 Refer to FCM's (Futures Commission Merchant) Income Statement of Taiwan, $-2008$.
We estimate the implied volatility through the Newton-Raphson method on the Black-Scholes (BS) model [10]. The Newton-Raphson method makes a guess for volatility, and then re-adjusts value by Vega. It uses the tangent to approximate the value, making use of the comparative bi-secant method, with faster convergence speed. Furthermore, depending on moneyness, we average one-day-ahead ( $t-1)$, five-day-ahead (t-5) and 20-day-ahead (t-20) ATM implied volatility as the ATM implied volatility forecasts for day $t$.

Instead of using the BS model to estimate IV, Dumas, Fleming, and Whaley develop a deterministic volatility function (DVF) option valuation model that has the potential of fitting the observed cross section of option price exactly [21]. Following Dumas, Fleming, and Whaley, we use the equation below:

$$
\begin{aligned}
\operatorname{Ln}\left(\sigma_{t}^{I V}\right)= & \alpha_{0}+\alpha_{1}\left(\frac{T X F}{K}\right)_{t}+\alpha_{2}\left(\frac{T X F}{K}\right)_{t}^{2} \\
& +\alpha_{3} T_{t}+\alpha_{4} T_{t}^{2}+\alpha_{5} T_{t} \cdot\left(\frac{T X F}{K}\right)_{t}+\varepsilon_{t}
\end{aligned}
$$

where $\alpha$ and $\varepsilon$ are the regression coefficients and error term, respectively [21]. Following Whaley and Lamoureux and Lastrapes, the daily IV for each option class is obtained by minimizing the mean squared error between the market (Price $^{\text {Market }}$ ) and theoretical price (Price ${ }^{\text {BSmodel }}$ ) of the BS model for all $\mathrm{N}$ number of observed option $\mathrm{i}$ on day $\mathrm{t}[51,38]$ :

$$
\underset{\alpha}{\operatorname{Min}}\left\{\frac{1}{N} \sum_{i=1}^{N}\left[\text { Price }_{t, i}^{\text {Market }}-\text { Price }_{t, i}^{\text {BSmodel }}\left(F_{t}, K_{t, i}, r_{t}, T_{t, i}, \sigma_{t, i}^{I V}\right)\right]^{2}\right\} .
$$

By minimizing the mean squared error, we can obtain a vector of parameter estimates, $\alpha=\left\{\alpha_{0}, \alpha_{1}, \alpha_{2}, \alpha_{3}, \alpha_{4}, \alpha_{5}\right\}$. Furthermore, suppose that we have an option trading on day $t$ with a given moneyness $M$ and maturity of T-t days, we can condition day t-k parameter vector $\alpha$, and forecast IV on day $\mathrm{t}$ for T-k day horizon. As done usually in IV forecasts, we average across the one-day-ahead (t-1), five-day-ahead (t-5) and 20-day-ahead (t-20) volatility estimates as day-t DVF volatility forecasts.

\subsection{Realized Volatility $\left(\sigma^{R V}\right)$}

Thanks to Canina and Figlewski discussion on unrelatedness between IV and future RV, many scholars use high frequency intraday data to calculate realized volatility in order to prove the forecasting ability of estimated volatility from historical data [13]. Furthermore, comparative study of various calculated volatilities will illuminate more information content from future volatility. Andersen and Bollerslev discover that high frequency data can construct more precise ex-post volatility estimates [2]. Andersen, Bollerslev, Diebold, and Labys (ABDL hereafter) argue that intraday returns provide better estimates of RV and 5-minute sampling is optimal, considering the impact of market microstructure factors on measures based on high-frequency data [4]. Similarly, Blair, Poon, and Taylor and Aït-Sahalia, Mykland and Zhang argue that if the microstructure noise is unaccounted for, the optimal sampling frequency is finite [11, 
1].

In ABDL, daily realized volatility of high-frequency data is defined by:

$$
\sigma_{t}^{2, R V}=\sum_{j}^{n} r_{j}^{2}
$$

where $r_{j}$ is the rate of return in interval $j$ on day $t$ and $n$ is the number of intervals in a day. For 9-minute sampling frequency, $n$ equals 30 in the Taiwan stock market. ABDL shows that five minute interval can obtain much better realized volatility. However, their underlying asset is foreign exchange which is different from ours. According to the matching stipulate of the Taiwan Stock Exchange, their buy and sell matching time takes place at least every 45 seconds. Therefore, we think the best decision interval for RV is 45 seconds. We will use multiples of 45 seconds to simulate stable realize volatility estimates.

The volatility, especially realized volatility, of many financial data series exhibits characteristics consistent with long memory behavior as discovered in previous studies. Although many stochastic processes could potentially exhibit the long memory property, the most widely used such process is the ARFIMA model [Granger and Joyeux, Granger, and Hosking] [28, 27, 30]. Andersen, Bollerslev, Diebold, and Labys and Andersen, Bollerslev, Diebold, and Ebens suggest that one can obtain better realized volatility through long-memory ARFIMA (autoregressive fractionally integrated moving average) time series model $[4,5,6]$. Koopman, Jungbacker, and Hol also discovers that an ARFIMA model can predict RV better than other models [37]. Therefore, we use the ARFIMA to describe the path of RVs to avoid estimation errors and low forecasting ability.

In the process of estimating an ARFIMA(p,d,q) model, the values of $p$ and $q$ must be determined before the value of $d$. Prior studies indicate that higher order of $\mathrm{p}$ and $\mathrm{q}$ can lead to high standard deviation of coefficients in the model. Some research uses ARMA $(1,1)$ or ARMA $(1,0)$ to describe RV with good fit. To avoid higher order $p$ and $q$ lowering the test power, we use an $\operatorname{ARFIMA}(1, \mathrm{~d}, 0)^{4}$ as the forecasting model for RV, where a stable value of $d$ is obtained through Bayesian estimation. Therefore, the ARFIMA $(1, \mathrm{~d}, 0)$ model can be specified as:

$$
(1-B)^{d} \operatorname{Ln}\left(\sigma_{t}^{R V}\right)=\omega_{0}+\omega_{1} \operatorname{Ln}\left(\sigma_{t-1}^{R V}\right)+e_{t},
$$

where B is backward shift operator, $\sigma_{t}^{R V}$ is the realized volatility, $\omega$ and $\mathrm{e}$ are the coefficient and error term, respectively. The fractional parameter d (between zero and one) represents a long memory structure, implying slow hyperbolic decay in autocorrelations.

Black, Christie, Schwert and Seguin and Cheung and $\mathrm{Ng}$ point out that there is a negative contemporary relationship between volatility change and rate of return, which can be explained by the leverage effect $[9,17,48,18]$. Therefore, for the leverage effect, we set up a dummy variable I, which is

4 Testing the ACF and PACF of the realized volatility shows that there is a good fit at $\mathrm{p}=1 / \mathrm{q}=0$. equal to 1 if the rate of return $\left(\mathrm{r}_{\mathrm{t}-\mathrm{l}}\right)$ in the previous period is less than zero, and zero otherwise (see Equation 12). Moreover, many studies also find that information with jump phenomenon will lead to unstable parameter estimation. Anderson, Bollerslev, Diebold, and Labys uses non-parametric method of the bi-power variation (BV) measure to isolate the jump element, which is non-negative, from the intraday data [5]. The $\mathrm{BV}$ measure can be calculated as follows:

$$
B V_{t}(\Delta) \equiv(\sqrt{2 / \pi})^{-2} \sum_{j=2}^{1 / \Delta}\left|r_{t+j \Delta, \Delta}^{2}\right|\left|r_{t+(j-1) \Delta, \Delta}^{2}\right|
$$

where $\Delta^{5}$ is the sampling frequency. Following the concept of $\sigma_{t+1}^{R V}(\Delta)-\mathrm{BV}_{\mathrm{t}+1}(\Delta) \rightarrow \sum_{\mathrm{t}<\mathrm{s}<\mathrm{t}+1} \kappa^{2}(\mathrm{~s})$, we can estimate Jump by $\kappa(t)$. Therefore, the Jump component $J$ is defined according to Andersen, Bollerslev and Diebold (2007) ${ }^{6}$ as:

$$
J_{t}=\operatorname{Max}\left[\sigma_{t}^{R V}-B V_{t}, 0\right]
$$

Thus, we specify an ARFIMA model that respectively incorporates leverage (ARFIMA + L), jump (ARFIMA $+J$ ), and both leverage and jump (ARFIMA+L/J) as follows:

$$
\begin{aligned}
& \text { ARFIMA }+\mathrm{L}:(1-\mathrm{B})^{\mathrm{d}} \operatorname{Ln}\left(\sigma_{\mathrm{t}}^{\mathrm{RV}}\right)=\omega_{0}+\omega_{1} \operatorname{Ln}\left(\sigma_{\mathrm{t}-1}^{\mathrm{RV}}\right), \\
& +\omega_{2} \operatorname{Ln}\left(\sigma_{\mathrm{t}-1}^{\mathrm{RV}}\right) \times \mathrm{I}_{\mathrm{r}_{\mathrm{t}-1}<0}+\mathrm{e}_{\mathrm{t}} \\
& \text { ARFIMA }+\mathrm{J}:(1-\mathrm{B})^{\mathrm{d}} \operatorname{Ln}\left(\sigma_{\mathrm{t}}^{\mathrm{RV}}\right)=\omega_{0}+\omega_{1} \operatorname{Ln}\left(\sigma_{\mathrm{t}-1}^{\mathrm{RV}}\right), \\
& +\beta^{\mathrm{Jump}} \mathrm{J}_{\mathrm{t}-1}+\mathrm{e}_{\mathrm{t}} \\
& \text { ARFIMA }+\mathrm{LJ}:(1-\mathrm{B})^{\mathrm{d}} \operatorname{Ln}\left(\sigma_{\mathrm{t}}^{\mathrm{RV}}\right)=\omega_{0}+\omega_{1} \operatorname{Ln}\left(\sigma_{\mathrm{t}-1}^{\mathrm{RV}}\right), \\
& +\omega_{2} \operatorname{Ln}\left(\sigma_{\mathrm{t}-1}^{\mathrm{RV}}\right) \times \mathrm{I}_{\mathrm{r}_{\mathrm{t}-1}<0}+\beta^{\mathrm{Jump}} \mathrm{J}_{\mathrm{t}-1}+\mathrm{e}_{\mathrm{t}}
\end{aligned}
$$

where $\omega, \beta^{\text {Jump }}$, e, B, I and $\mathrm{r}$ are the coefficient, jump coefficient, error term, backward shift operator, dummy variable and index return, respectively. Hosking (1981) investigates the likely value of long-memory parameter for ARFIMA model, and discovers that for $-0.5<\mathrm{d}<0.5$ the process is stationary and invertible. If $-0.5<\mathrm{d}<0$, the process is said to exhibit anti-persistence because the autocorrelations are negative. If $0<\mathrm{d} \leqq 0.5$, the process exhibits long-memory. The most prevalent method ${ }^{7}$ for estimating the fractional differencing parameter is the two-step procedure proposed by Geweke and Porter-Hudak (GPH) [26]. The value of d should be estimated first and then used as an input variable to estimate all parameter values in the model, because it is wrong to treat endogenous variables as input variables in the model. Koop, Ley, Osiewalski and Steel suggest that using Bayesian method to estimate all parameter values simultaneously provides more

\footnotetext{
5 For example, for realized volatility constructed in the 9-minute intervals, eliminating effects from the first and last time period, there are 28 regions, then $\Delta=1 / 28=0.0357$

6 " $\mathrm{J}$ " is a jump measure estimated using high frequency data according to the theory of quadratic variations (see Andersen, Bollerslev and Diebold [3]).

7 See Geweke and Porter-Hudak and Janacek for details [26, 31].
} 
reliable estimates [36]. Therefore, we use Bayesian method to estimate the value of $d$ in the ARFIMA model.

\section{Empirical Results}

\subsection{Volatility and Its Forecasts}

While some prior studies [e.g., ABDL (2003), Pong et al. (2004)] use a 30-minute interval to estimate realized volatility, we use the interval of one minute in the very last year of the sample period. The RV value is close to $12 \%$. The RV for the non-overlapping 45- second multiples of 6 (RV6), 9 (RV9), 12 (RV12), and 30 (RV30) minutes interval appears to be quite consistent and stable, as in Figure 2. Table 1 lists all summary statistics for all realized volatilities. We find that the estimate of RV3 (3-minute interval) differs the most between index futures and spot index, while the estimate of RV30 differs the least and is highly stable.

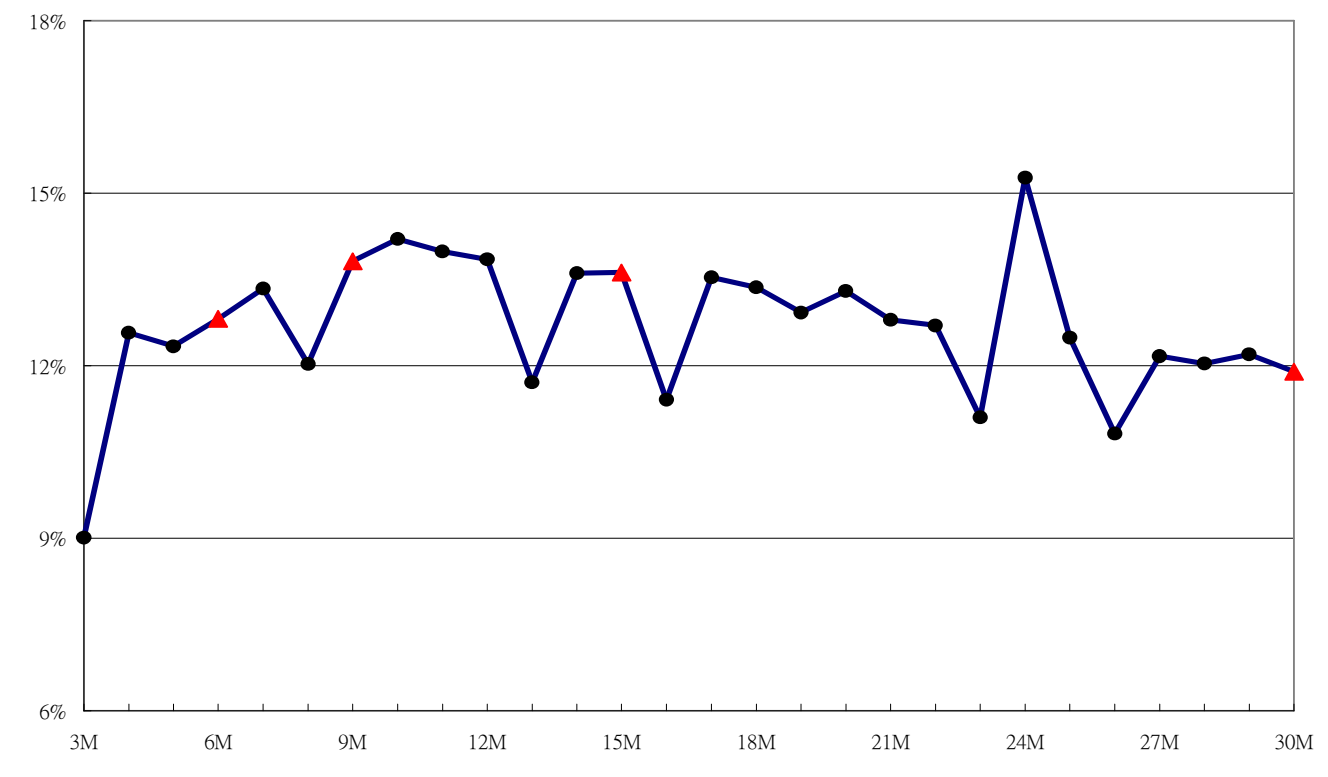

Figure 2. The TAIEX realized volatility over different sampling frequencies.

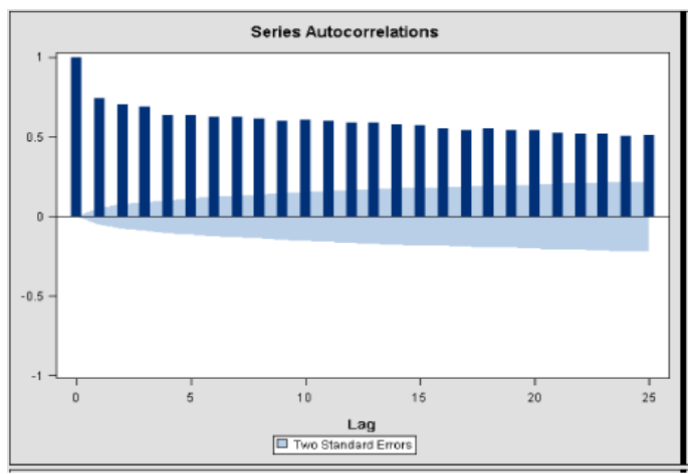

RV6

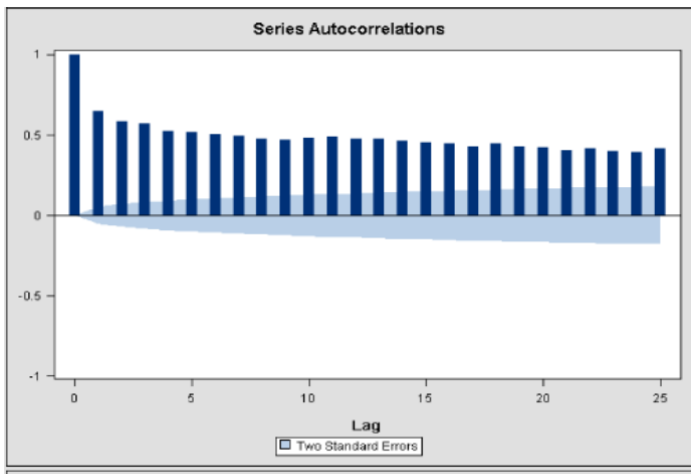

RV15

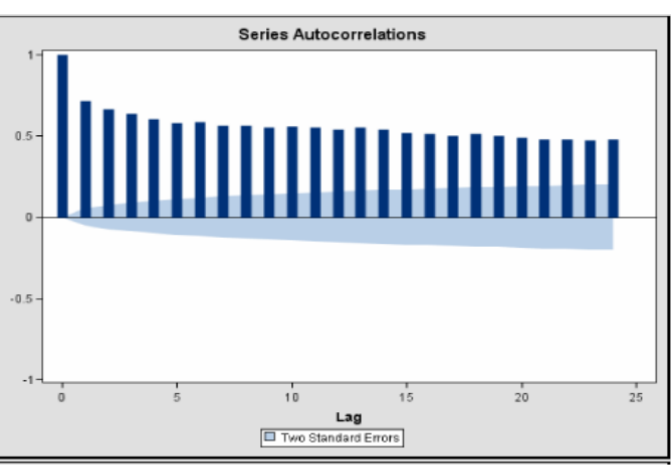

RV9

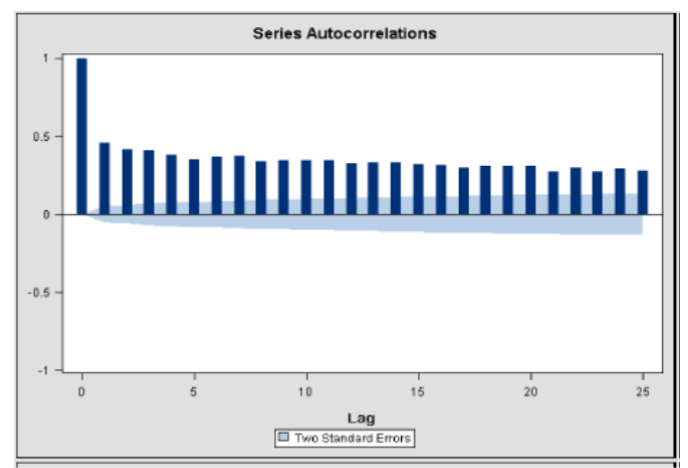

RV30

Figure 3. The autocorrelation function of realized volatility. 


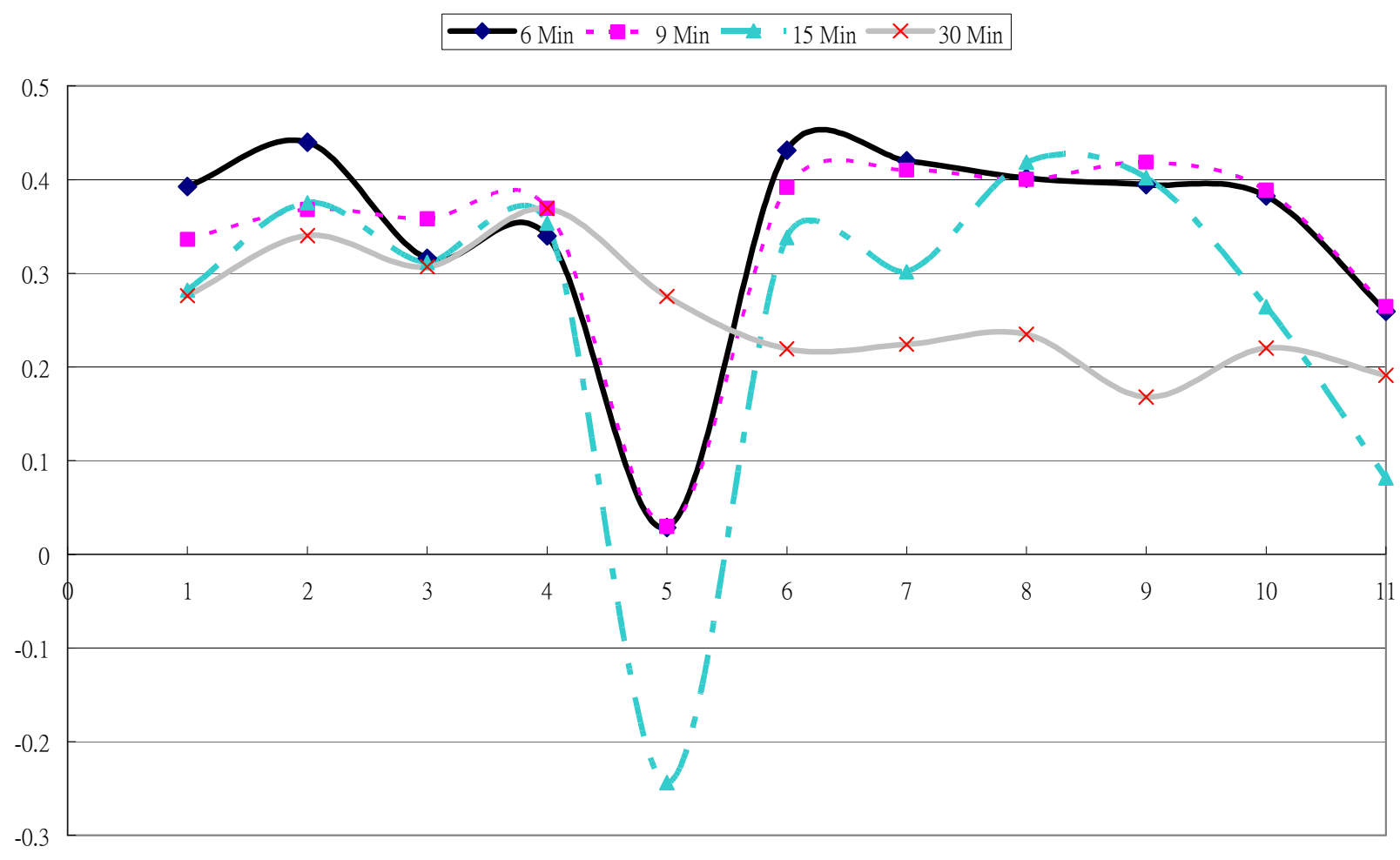

Figure 4. The estimated values of parameter $d$ in the ARFIMA $(1, d, 0)$ model for different realized volatilities in various moving periods.

Table 1. Summary statistics of realized volatility and historical volatility for TAIEX and TX.

\begin{tabular}{llllllll}
\hline Index & Variable & RV3 & RV6 & RV9 & RV15 & RV30 & HV \\
\hline \multirow{5}{*}{ TAIEX } & Means (1) & $9.37 \%$ & $12.36 \%$ & $13.27 \%$ & $13.10 \%$ & $11.91 \%$ & $20.84 \%$ \\
& Volatility & $3.82 \%$ & $5.63 \%$ & $6.11 \%$ & $6.15 \%$ & $5.66 \%$ & $2.65 \%$ \\
& Maximum & $26.06 \%$ & $40.10 \%$ & $43.57 \%$ & $45.77 \%$ & $50.75 \%$ & $26.15 \%$ \\
& Minimum & $2.25 \%$ & $2.19 \%$ & $1.85 \%$ & $2.22 \%$ & $1.88 \%$ & $15.10 \%$ \\
& Median & $9.06 \%$ & $11.05 \%$ & $11.85 \%$ & $11.61 \%$ & $9.60 \%$ & $20.65 \%$ \\
& Skew & 0.5971 & 1.0539 & 1.1512 & 1.2593 & 1.7316 & -0.0325 \\
& Kurt & 0.1147 & 1.2631 & 1.6276 & 2.0129 & 5.2991 & -0.6868 \\
TX & Means (2) & $22.97 \%$ & $19.62 \%$ & $18.17 \%$ & $15.82 \%$ & $12.50 \%$ & $24.18 \%$ \\
& Volatility & $17.14 \%$ & $14.55 \%$ & $13.37 \%$ & $11.65 \%$ & $9.26 \%$ & $4.23 \%$ \\
& MAX & $98.95 \%$ & $99.53 \%$ & $96.30 \%$ & $89.54 \%$ & $75.51 \%$ & $33.94 \%$ \\
DIFF(2)-(1) & MIN & $4.40 \%$ & $4.20 \%$ & $3.86 \%$ & $0.00 \%$ & $0.00 \%$ & $14.63 \%$ \\
& Median & $17.06 \%$ & $14.72 \%$ & $13.76 \%$ & $12.31 \%$ & $10.00 \%$ & $24.93 \%$ \\
& Skew & 1.8382 & 2.2753 & 2.2636 & 2.4699 & 2.4934 & -0.2176 \\
& Kurt & 3.4545 & 6.3858 & 6.5181 & 8.1449 & 9.1175 & 0.1643 \\
\end{tabular}

This table provides summary statistics for realized volatility of TAIEX and TX across five sample interval period (RV3, RV6, RV9, RV15 and RV30) and historical volatility (HV) of TAIEX and TX.

We find from Figure 3 that the ACF (autocorrelation function) for four realized volatilities diminish to zero much more slowly than the ARMA process. This is consistent with Hosking's (1981) finding about the long memory property. To obtain a stable value of $d$ (the fractional difference), we use an $\operatorname{ARFIMA}(1, \mathrm{~d}, 0)$ model with in-sample data every half year to calculate the moving average of the $d$ value. As shown in Figure 4, 12 moving averages of the $d$ values are obtained. The moving average of the $d$ values appear to be quite stable from number 6 to number 10 . The average $d$ value is 0.406 for 6 minutes; 0.4018 for 9 minutes; 0.345 for 15 minutes; and 0.2133 for 30 minutes. They are all in the long memory region of $0<\mathrm{d}<0.5$. We can thus confirm the long memory property for the TAIEX volatility through Bayesian estimation of the $d$ values. Comparing $\mathrm{d}$ values of the four realized volatilities, we also find that RV9 and RV30 volatilities are relatively lower. As such, we will continue to use RV9 and RV30 in further tests.

Table 2 gives all statistics for the IV average values. It shows higher IV estimates and standard deviations for the nearby contracts. These volatilities exhibit much more information content with the skewness and kurtosis approximating normal distribution, as typically assumed in the options literature. 
Table 2. Summary statistics of implied volatility with different moneyness.

\begin{tabular}{llllllll}
\hline \multirow{2}{*}{ Maturity } & Moneyness & All & \multicolumn{3}{c}{ ATM } & & \\
\cline { 2 - 8 } & Variables & $\sigma^{I V}$ & $\sigma_{\text {Call }}^{I V}$ & $\sigma_{\text {Put }}^{I V}$ & $\sigma^{I V}$ & $\sigma_{\text {Call }}^{I V}$ & $\sigma_{\text {Put }}^{I V}$ \\
\hline \multirow{6}{*}{ All } & Means & $29.47 \%$ & $29.78 \%$ & $29.14 \%$ & $28.91 \%$ & $28.67 \%$ & $29.15 \%$ \\
& Volatility & $4.12 \%$ & $4.20 \%$ & $4.23 \%$ & $4.28 \%$ & $4.58 \%$ & $4.29 \%$ \\
& Maximum & $43.34 \%$ & $43.69 \%$ & $43.05 \%$ & $44.61 \%$ & $44.61 \%$ & $44.61 \%$ \\
& Minimum & $21.84 \%$ & $21.70 \%$ & $20.73 \%$ & $21.48 \%$ & $19.67 \%$ & $20.22 \%$ \\
& Median & $29.03 \%$ & $29.90 \%$ & $28.35 \%$ & $28.67 \%$ & $28.92 \%$ & $28.24 \%$ \\
& Skew & 0.9391 & 0.6571 & 1.0735 & 0.7922 & 0.4393 & 0.9614 \\
& Kurtosis & 1.5318 & 0.9318 & 1.8735 & 1.3347 & 0.8764 & 1.6162 \\
& Means & $31.01 \%$ & $30.44 \%$ & $31.38 \%$ & $29.10 \%$ & $28.79 \%$ & $29.42 \%$ \\
& Volatility & $4.75 \%$ & $5.09 \%$ & $5.08 \%$ & $4.35 \%$ & $4.68 \%$ & $4.38 \%$ \\
& Maximum & $45.73 \%$ & $45.23 \%$ & $46.38 \%$ & $44.61 \%$ & $44.61 \%$ & $44.61 \%$ \\
& Minimum & $22.14 \%$ & $20.16 \%$ & $21.30 \%$ & $21.48 \%$ & $20.29 \%$ & $20.22 \%$ \\
& Median & $30.26 \%$ & $30.37 \%$ & $30.51 \%$ & $28.72 \%$ & $28.92 \%$ & $28.45 \%$ \\
& Skew & 0.8876 & 0.5492 & 0.9728 & 0.7167 & 0.3629 & 0.8884 \\
& Kurtosis & 1.0046 & 0.6112 & 1.0261 & 0.9934 & 0.5954 & 1.1592 \\
\hline
\end{tabular}

This table provides summary statistics for implied volatility across two moneyness and two maturities in TXO. ATM are options where $0.97<\mathrm{M}<1.03$. Nearby are options contract with a maturity period of 8 to 30 days. Options with maturity longer than 2 months are excluded because of light trading activities.

Table 3. Summary statistic of forecasting estimators on various volatilities.

\begin{tabular}{|c|c|c|c|c|c|c|}
\hline Statistics & $\sigma_{A T M-A l l}^{I V}$ & $\boldsymbol{\sigma}_{A T M-C a l l}^{I V}$ & $\sigma_{A T M-P u t}^{I V}$ & $\sigma_{A l l}^{D V F}$ & $\sigma_{\text {Call }}^{D V F}$ & $\sigma_{P u t}^{D V F}$ \\
\hline Means & $29.04 \%$ & $28.66 \%$ & $30.81 \%$ & $29.99 \%$ & $29.69 \%$ & $30.55 \%$ \\
\hline Volatility & $2.39 \%$ & $3.06 \%$ & $2.52 \%$ & $3.16 \%$ & $4.07 \%$ & $3.04 \%$ \\
\hline Maximum & $35.88 \%$ & $37.84 \%$ & $39.05 \%$ & $39.75 \%$ & $42.36 \%$ & $41.38 \%$ \\
\hline Minimum & $22.74 \%$ & $21.54 \%$ & $25.54 \%$ & $23.49 \%$ & $15.98 \%$ & $24.55 \%$ \\
\hline Median & $29.02 \%$ & $28.86 \%$ & $30.53 \%$ & $29.79 \%$ & $29.86 \%$ & $30.43 \%$ \\
\hline Skew & 0.0753 & 0.1183 & 0.7275 & 0.3058 & -0.2783 & 0.6093 \\
\hline Kurtosis & -0.0499 & 0.4737 & 0.6232 & 0.1189 & 1.0188 & 0.6675 \\
\hline
\end{tabular}

\begin{tabular}{|c|c|c|c|c|c|c|}
\hline Statistics & $\sigma_{\text {TAIEX }}^{R V 9}$ & $\sigma_{\text {TAIEX }}^{R V 30}$ & $\sigma_{\text {TAIEX }}^{H V}$ & $\sigma_{T X}^{R V 9}$ & $\sigma_{T X}^{R V 30}$ & $\sigma_{T X}^{H V}$ \\
\hline Means & $19.97 \%$ & $16.24 \%$ & $20.25 \%$ & $22.18 \%$ & $17.36 \%$ & $23.26 \%$ \\
\hline Volatility & $3.32 \%$ & $3.57 \%$ & $1.50 \%$ & $5.28 \%$ & $4.48 \%$ & $2.94 \%$ \\
\hline Maximum & $32.71 \%$ & $28.74 \%$ & $23.22 \%$ & $40.65 \%$ & $30.39 \%$ & $29.94 \%$ \\
\hline Minimum & $11.96 \%$ & $9.15 \%$ & $16.96 \%$ & $12.04 \%$ & $8.05 \%$ & $16.94 \%$ \\
\hline Median & $19.46 \%$ & $15.65 \%$ & $20.02 \%$ & $21.51 \%$ & $17.10 \%$ & $24.31 \%$ \\
\hline Kurtosis & 2.4335 & 0.4126 & -0.5497 & 2.1102 & 0.3746 & -0.6084 \\
\hline
\end{tabular}

This table provides summary statistics for estimated values of volatility based on volatility forecasts from different forecasting methods. These estimated values are observed on $\mathrm{t}-1, \mathrm{t}-5$, and $\mathrm{t}-20$ days from different forecasting method. ATM are options where $0.97<\mathrm{M}<1.03$. All options are with a maturity period of 8 to 30 days. Options with maturity longer than 2 months are excluded because of light trading activities. Estimated RV employs the 9-minute interval (RV9) and 30-minute interval (RV30).

Table 4. Summary statistic of forecasting estimator for RV using ARFIMA $(1, d, 0)$ models.

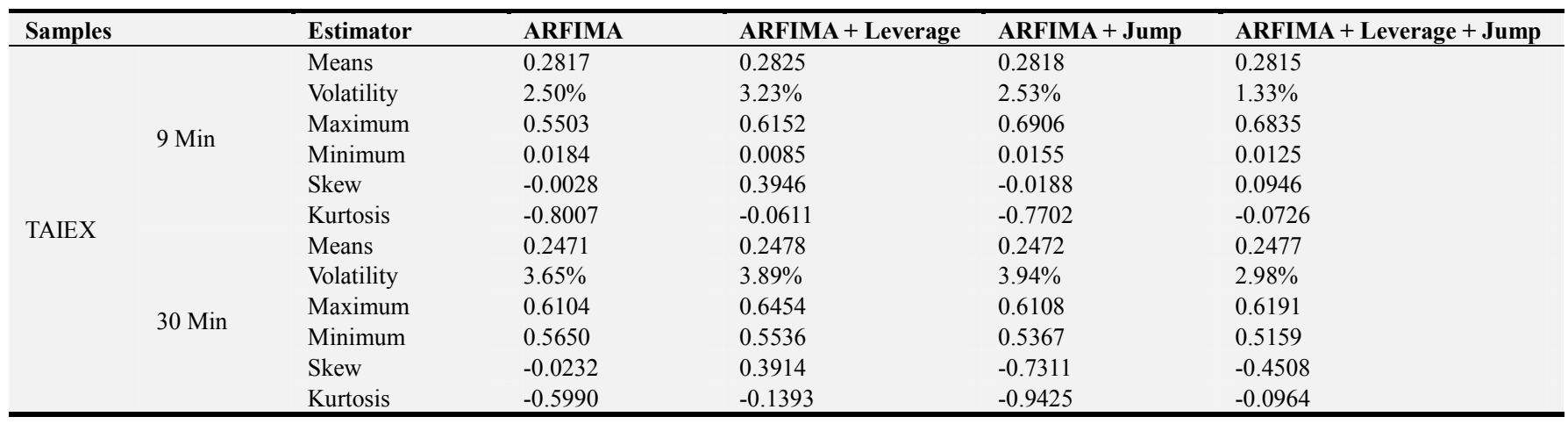




\begin{tabular}{llllll}
\hline Samples & Estimator & ARFIMA & ARFIMA + Leverage & ARFIMA + Jump & ARFIMA + Leverage + Jump \\
\hline \multirow{4}{*}{9 Min } & Means & 0.2956 & 0.3057 & 0.3008 & 0.3025 \\
& Volatility & $5.65 \%$ & $5.98 \%$ & $5.48 \%$ & $5.01 \%$ \\
& Maximum & 0.6508 & 0.6954 & 0.7011 & 0.7152 \\
& Minimum & 0.0298 & 0.0350 & 0.0300 & 0.0201 \\
TX & Skew & -0.0018 & 0.3598 & -0.0145 & 0.1146 \\
& Kurtosis & -0.9116 & -0.0784 & -0.8510 & -0.0756 \\
& Means & 0.2800 & 0.3000 & 0.2900 & 0.2988 \\
& Volatility & $5.87 \%$ & $6.21 \%$ & $6.45 \%$ & $6.15 \%$ \\
& Maximum & 0.6956 & 0.7011 & 0.7135 & 0.7013 \\
& Minimum & 0.0199 & 0.0100 & 0.0018 & 0.0101 \\
& Min & -0.0119 & 0.4544 & -0.1568 & 0.1987 \\
& Skew & -0.9975 & -0.0985 & -0.9570 & -0.0987 \\
\hline
\end{tabular}

This table provides summary statistics for estimated RV from TAIEX and TX based on various ARFIMA related models.

Table 3 presents estimated values for various volatilities. These average estimated values are observed on $\mathrm{t}-1, \mathrm{t}-5$, and $\mathrm{t}-20$ days. They are the proxy predictor variables for all information known up to day t. We find that the standard deviation of forecasted values is less than that of estimated value. It is because of previous information on average values contained in forecasted values. From the kurtosis and skewness coefficients of the forecasted values, we find that most time series exhibit normal distribution except RV9's forecasted values for the spot index and index futures, which shows right skewness and high kurtosis. Table 4 shows forecasted values of realized volatility using a fitted ARFIMA model. We find higher RV values, especially higher RV9. The RV series using the fitted ARFIMA follows the normal distribution.

\subsection{Encompassing Regression Results}

In an encompassing regression, if the information contained in independent variables can completely explain the dependent variable, the market is deemed efficient. So, all regression coefficients are significant, positive, and less than one, and should sum up to one. It means the dependent variable is completely explained by the independent variables. It also implies that the encompassing regression models are good quality volatility forecasting models. Moreover, we can observe the information contents in different volatility via regression coefficients.

The majority of the prior studies on volatility forecasting concludes that the forecasting ability of historical volatility (HV) is inferior to that of implied volatility (IV). Surprisingly, Table 5 shows that HV comes first in power of explanation, followed by IV, in forecasting RV. It seems that DVFIV does not have superior forecasting power for RV. This is in agreement with Dumas, Fleming, and Whaley with regards to DVFIV as described above [21].

Table 5. Encompassing regression tests for realized volatility.

\begin{tabular}{|c|c|c|c|c|c|c|c|c|c|c|c|c|c|c|}
\hline Dependent & $\beta_{0}$ & & $\beta_{1 \text { (TAIEX) }}$ & & $\beta_{1(\mathrm{TX})}$ & & \multirow{2}{*}{$\begin{array}{l}\boldsymbol{\beta}_{\mathbf{2}} \\
0.332 \\
(4.53)\end{array}$} & \multirow[b]{2}{*}{$* * *$} & \multicolumn{2}{|l|}{$\beta_{3}$} & \multicolumn{2}{|l|}{ F } & \multirow{2}{*}{$\begin{array}{l}\mathbf{R}^{2} \\
0.47\end{array}$} & $\sigma^{\text {option }}$ \\
\hline \multirow{6}{*}{ RV9 } & $\begin{array}{l}-0.168 \\
(-2.73)\end{array}$ & $* * *$ & \multirow[t]{2}{*}{$\begin{array}{l}0.498 \\
(11.57)\end{array}$} & \multirow[t]{2}{*}{$* * *$} & \multirow[b]{2}{*}{$\begin{array}{l}0.412 \\
(12.04)\end{array}$} & \multirow[b]{2}{*}{$* * *$} & & & $\begin{array}{l}0.116 \\
(2.86)\end{array}$ & $* * *$ & 410.38 & $* * *$ & & \multirow{2}{*}{ All } \\
\hline & $\begin{array}{l}-0.171 \\
(-3.51)\end{array}$ & $* * *$ & & & & & $\begin{array}{l}0.339 \\
(4.12)\end{array}$ & $* * *$ & $\begin{array}{l}0.110 \\
(2.62)\end{array}$ & $* * *$ & 409.11 & $* * *$ & 0.47 & \\
\hline & $\begin{array}{l}-0.113 \\
(-1.98)\end{array}$ & $* *$ & $\begin{array}{l}0.503 \\
(12.96)\end{array}$ & $* * *$ & & & $\begin{array}{l}0.318 \\
(6.31)\end{array}$ & $* * *$ & $\begin{array}{l}0.260 \\
(3.53)\end{array}$ & $* * *$ & 436.35 & $* * *$ & 0.49 & \\
\hline & $\begin{array}{l}-0.106 \\
(-1.88)\end{array}$ & $* *$ & & & $\begin{array}{l}0.495 \\
(12.71)\end{array}$ & $* * *$ & $\begin{array}{l}0.326 \\
(4.55)\end{array}$ & $* * *$ & $\begin{array}{l}0.198 \\
(2.69)\end{array}$ & $* * *$ & 395.07 & $* * *$ & 0.46 & Call \\
\hline & $\begin{array}{l}-0.197 \\
(-3.14)\end{array}$ & $* * *$ & $\begin{array}{l}0.680 \\
(18.77)\end{array}$ & $* * *$ & & & $\begin{array}{l}0.205 \\
(3.46)\end{array}$ & $* * *$ & $\begin{array}{l}0.071 \\
(1.09)\end{array}$ & & 389.15 & $* * *$ & 0.46 & D. \\
\hline & $\begin{array}{l}-0.189 \\
(-2.94)\end{array}$ & $* * *$ & & & $\begin{array}{l}0.601 \\
(19.53)\end{array}$ & $* * *$ & $\begin{array}{l}0.197 \\
(4.69)\end{array}$ & $* * *$ & $\begin{array}{l}0.090 \\
(1.17)\end{array}$ & & 451.87 & $* * *$ & 0.51 & Put \\
\hline & $\begin{array}{l}-0.723 \\
(-9.40)\end{array}$ & $* * *$ & $\begin{array}{l}0.358 \\
(7.09)\end{array}$ & $* * *$ & & & $\begin{array}{l}0.477 \\
(5.19)\end{array}$ & $* * *$ & $\begin{array}{l}0.020 \\
(0.21)\end{array}$ & & 194.71 & $* * *$ & 0.30 & ull \\
\hline & $\begin{array}{l}-0.657 \\
(-9.06)\end{array}$ & $* * *$ & & & $\begin{array}{l}0.312 \\
(6.67)\end{array}$ & $* * *$ & $\begin{array}{l}0.485 \\
(4.57)\end{array}$ & $* * *$ & $\begin{array}{l}0.091 \\
(0.10)\end{array}$ & & 201.55 & $* * *$ & 0.29 & All \\
\hline & $\begin{array}{l}-0.622 \\
(-8.62)\end{array}$ & $* * *$ & $\begin{array}{l}0.426 \\
(8.95)\end{array}$ & $* * *$ & & & $\begin{array}{l}0.338 \\
(5.31)\end{array}$ & $* * *$ & $\begin{array}{l}0.141 \\
(1.51)\end{array}$ & & 200.87 & $* * *$ & 0.30 & \\
\hline RV30 & $\begin{array}{l}-0.604 \\
(-8.71)\end{array}$ & $* * *$ & & & $\begin{array}{l}0.405 \\
(6.54)\end{array}$ & $* * *$ & $\begin{array}{l}0.342 \\
(4.28)\end{array}$ & $* * *$ & $\begin{array}{l}0.101 \\
(1.03)\end{array}$ & & 171.61 & $* * *$ & 0.24 & Call \\
\hline & $\begin{array}{l}-0.741 \\
(-9.51)\end{array}$ & $* * *$ & $\begin{array}{l}0.544 \\
(12.45)\end{array}$ & $* * *$ & & & $\begin{array}{l}0.307 \\
(4.18)\end{array}$ & $* * *$ & $\begin{array}{l}-0.075 \\
(-0.93)\end{array}$ & & 185.78 & $* * *$ & 0.29 & \\
\hline & $\begin{array}{l}-0.669 \\
(-9.17)\end{array}$ & $* * *$ & & & $\begin{array}{l}0.517 \\
(13.38)\end{array}$ & $* * *$ & $\begin{array}{l}0.301 \\
(4.59)\end{array}$ & $* * *$ & $\begin{array}{l}0.021 \\
(0.16)\end{array}$ & & 222.34 & $* * *$ & 0.32 & Put \\
\hline
\end{tabular}

Note: $*, * *$, and $* * *$ indicate significance at the $10 \%, 5 \%$, and $1 \%$ levels, respectively.

The encompassing regression model is specified as follows (RV model): 
$\operatorname{Ln}\left(\sigma_{t}^{\mathrm{RV}}\right)=\beta_{0}+\beta_{1} \operatorname{Ln}\left(\sigma_{\mathrm{t} \mid \Omega_{\mathrm{t}-1}}^{\mathrm{HV}}\right)+\beta_{2} \operatorname{Ln}\left(\sigma_{\mathrm{t} \mid \Omega_{\mathrm{t}-1}^{\mathrm{IV}} \cdot \mathrm{ATM}^{\mathrm{e}}}\right)+\beta_{3} \operatorname{Ln}\left(\sigma_{\mathrm{t} \mid \Omega_{\mathrm{t}-1}}^{\mathrm{DVFVV}^{\mathrm{e}}}\right)+\varepsilon_{\mathrm{t}}$ where $\beta, \varepsilon$ and $\Omega_{\mathrm{t}-1}$ are the regression coefficients, error term, and information collected at time $\mathrm{t}-1$, respectively. $\sigma_{\mathrm{t} \mid \Omega_{\mathrm{t}-1}}^{\mathrm{HV}}$, $\sigma_{\mathrm{t} \mid \Omega_{\mathrm{t}-1}}^{\mathrm{IVATM}^{\mathrm{e}}}$ and $\sigma_{\mathrm{t} \mid \Omega_{\mathrm{t}-1}}^{\mathrm{DVFIV}^{\mathrm{e}}}$ respectively are the day-t predictors of historical volatility (HV), ATM implied volatility (IV) and implied volatility computed by the deterministic volatility models (DVFIV), conditional on information at day $\mathrm{t}-1 . \sigma_{\mathrm{t}}^{\mathrm{RV}}$ is realized volatility (RV). The superscript e stands for forecast value. Dependent variables (RV) are estimated using the 9-minute interval and 30-minute interval.

Table 6. Encompassing regression tests for implied volatility.

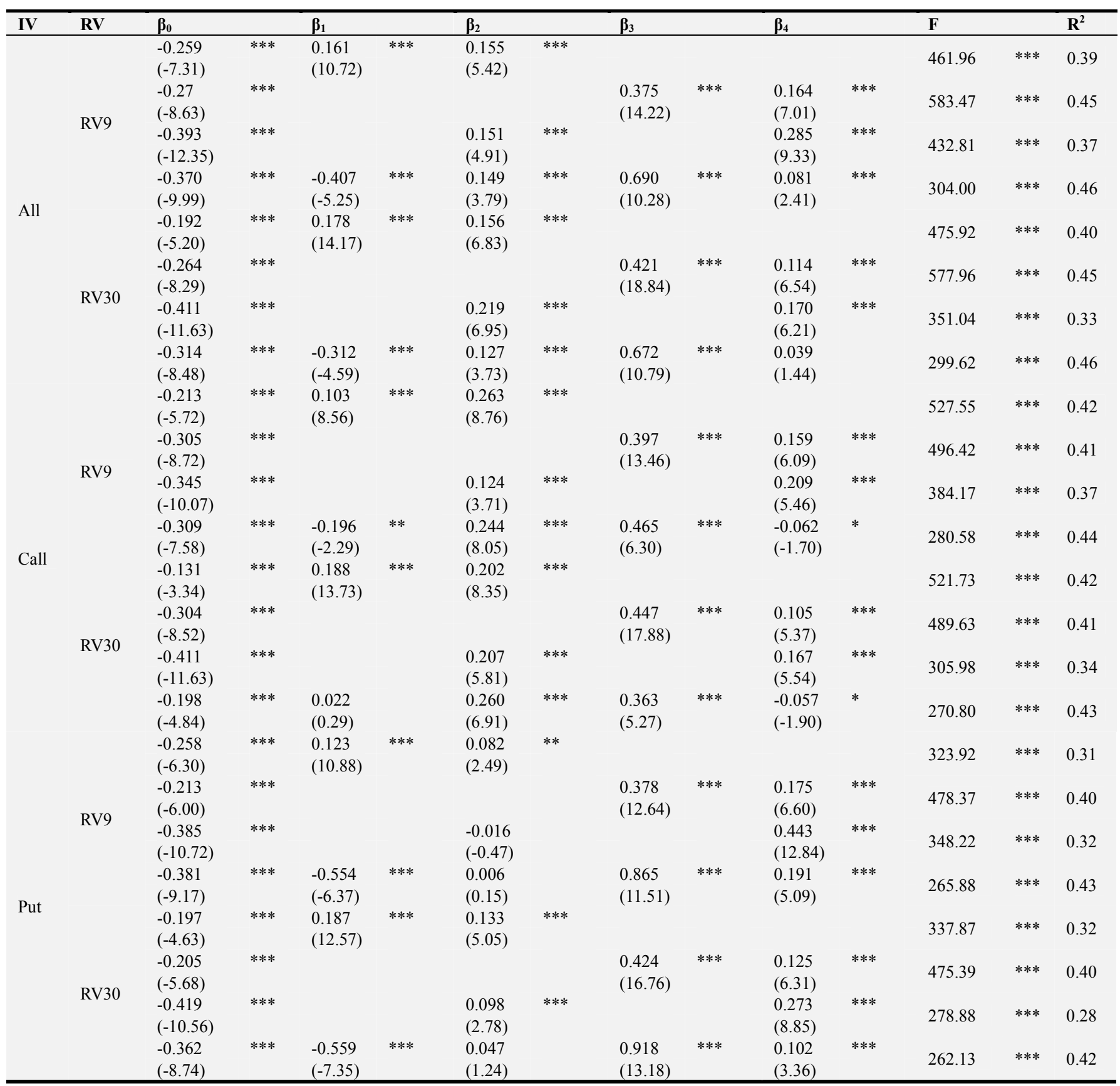

Note: $* * *$, and $* * *$ indicate significance at the $10 \%, 5 \%$, and $1 \%$ levels, respectively.

The encompassing regression model is specified as follows (IV-RV model):

$$
\begin{aligned}
& \operatorname{Ln}\left(\sigma_{t}^{\mathrm{IV}}\right)=\beta_{0}+\beta_{1} \operatorname{Ln}\left(\sigma_{t \mid \Omega_{t-1}}^{\text {TAIEX.HV }}\right)+\beta_{2} \operatorname{Ln}\left(\sigma_{t \mid \Omega_{t-1}}^{\text {TAIEX.RV }}\right) \\
& +\beta_{3} \operatorname{Ln}\left(\sigma_{t \mid \Omega_{t-1}}^{\text {TX.HVe }}\right)+\beta_{4} \operatorname{Ln}\left(\sigma_{t \mid \Omega_{t-1}}^{\text {TX.RVe }}\right)+\varepsilon_{t}
\end{aligned}
$$

where $\beta, \varepsilon$ and $\Omega_{\mathrm{t}-1}$ are the regression coefficients, error term, and information collected at time $\mathrm{t}-1$, respectively. $\sigma_{\mathrm{t}}^{\mathrm{IV}}$ is implied volatility. $\sigma_{t}^{\mathrm{TX}-\mathrm{HV}}$ and $\sigma_{\mathrm{t}}^{\mathrm{TX}-\mathrm{RV}}$ are respectively historical volatility and realized volatility of TAIEX. $\sigma_{t}^{\mathrm{TX}-\mathrm{HV}}$ 
and $\sigma_{t}^{\mathrm{TX}-\mathrm{RV}}$ are respectively historical volatility and realized volatility of TX. The superscript e stands for forecast value. RVs are estimated using the 9-minute interval and 30-minute interval. All options are with a maturity of 8 to 30 days.

We believe the high explanatory power of HV derives from better HV estimates obtained from the ARMA model. The prior literature suggests that futures market leads spot market. Our empirical results show that the spot market HV can explain RV much better than the futures market HV. This is anticipated owing to the fact that we use the same sample to estimate RV and spot market HV. IV can explain RV as well as HV when call options are lumped together with put options. However, when a call option is separated from a put option, IV has lower ability to explain RV, while $\mathrm{HV}$ possesses higher ability in explaining RV. Table 5 implies that HV of spot and futures market is an unbiased estimator of RV. It is very important for option traders whether $\mathrm{HV}$ and RV are unbiased estimators of IV. Table 6 compares spot index volatility and index futures volatility in explaining IV. However, spot volatility becomes less predictive of IV once futures market $\mathrm{HV}$ and $\mathrm{RV}$ are included. Of all the explanatory variables, futures market $\mathrm{HV}$ is the best in explaining IV, while the coefficient for spot market HV becomes negative. Neither spot market RV nor futures market RV can forecast IV better than $\mathrm{HV}$, even though the spot market RV performs less satisfactorily than futures market RV as an independent variable.

Table 7. Encompassing regression tests for implied volatility using the IV-ARV model.

\begin{tabular}{|c|c|c|c|c|c|c|c|c|c|c|c|c|c|c|}
\hline IV & ARV variables & $\boldsymbol{\beta}_{0}$ & & $\beta_{1}$ & & $\boldsymbol{\beta}_{2}$ & & $\beta_{3}$ & & $\boldsymbol{\beta}_{4}$ & & $\mathbf{F}$ & & $\mathbf{R}^{2}$ \\
\hline \multirow{8}{*}{ All } & ARV9 & $\begin{array}{l}-0.359 \\
(-5.15)\end{array}$ & $* * *$ & $\begin{array}{l}-0.012 \\
(-1.27)\end{array}$ & & $\begin{array}{l}0.188 \\
(2.45)\end{array}$ & $* *$ & $\begin{array}{l}0.417 \\
(9.58)\end{array}$ & $* * *$ & $\begin{array}{l}0.199 \\
(2.00)\end{array}$ & $*$ & 411.25 & $* * *$ & 0.35 \\
\hline & ARV9+J & $\begin{array}{l}-0.339 \\
(-5.54)\end{array}$ & $* * *$ & $\begin{array}{l}-0.019 \\
(-1.12)\end{array}$ & & $\begin{array}{l}0.201 \\
(3.99)\end{array}$ & $* * *$ & $\begin{array}{l}0.356 \\
(9.12)\end{array}$ & $* * *$ & $\begin{array}{l}0.371 \\
(2.54)\end{array}$ & $* *$ & 498.19 & $* * *$ & 0.40 \\
\hline & ARV9+L & $\begin{array}{l}-0.398 \\
(-5.89)\end{array}$ & $* * *$ & $\begin{array}{l}-0.011 \\
(-1.50)\end{array}$ & & $\begin{array}{l}0.149 \\
(1.90)\end{array}$ & * & $\begin{array}{l}0.519 \\
(9.26)\end{array}$ & $* * *$ & $\begin{array}{l}0.175 \\
(1.10)\end{array}$ & & 300.35 & $* * *$ & 0.31 \\
\hline & ARV9+J/L & $\begin{array}{l}-0.342 \\
(-5.10)\end{array}$ & $* * *$ & $\begin{array}{l}-0.017 \\
(-1.17)\end{array}$ & & $\begin{array}{l}0.104 \\
(1.81)\end{array}$ & $*$ & $\begin{array}{l}0.490 \\
(9.10)\end{array}$ & $* * *$ & $\begin{array}{l}0.093 \\
(1.89)\end{array}$ & $*$ & 351.01 & $* * *$ & 0.35 \\
\hline & ARRV30 & $\begin{array}{l}-0.304 \\
(-4.41)\end{array}$ & $* * *$ & $\begin{array}{l}-0.201 \\
(-1.79)\end{array}$ & $*$ & $\begin{array}{l}0.180 \\
(1.93)\end{array}$ & * & $\begin{array}{l}0.451 \\
(10.19)\end{array}$ & $* * *$ & $\begin{array}{l}0.101 \\
(2.10)\end{array}$ & $*$ & 256.75 & $* * *$ & 0.21 \\
\hline & ARV30+J & $\begin{array}{l}-0.249 \\
(-3.94)\end{array}$ & $* * *$ & $\begin{array}{l}-0.100 \\
(-0.59)\end{array}$ & & $\begin{array}{l}0.198 \\
(2.54)\end{array}$ & $* *$ & $\begin{array}{l}0.380 \\
(9.51)\end{array}$ & $* * *$ & $\begin{array}{l}0.305 \\
(3.58)\end{array}$ & $* *$ & 278.02 & $* * *$ & 0.25 \\
\hline & ARV30+L & $\begin{array}{l}-0.298 \\
(-3.82)\end{array}$ & $* * *$ & $\begin{array}{l}-0.215 \\
(-2.01)\end{array}$ & $*$ & $\begin{array}{l}0.101 \\
(1.89)\end{array}$ & $*$ & $\begin{array}{l}0.592 \\
(10.16)\end{array}$ & $* * *$ & $\begin{array}{l}0.109 \\
(0.92)\end{array}$ & & 200.54 & $* * *$ & 0.19 \\
\hline & ARV30+J/L & $\begin{array}{l}-0.208 \\
(-3.95)\end{array}$ & $* * *$ & $\begin{array}{l}-0.156 \\
(-1.06)\end{array}$ & & $\begin{array}{l}0.128 \\
(1.90)\end{array}$ & $*$ & $\begin{array}{l}0.490 \\
(10.01)\end{array}$ & $* * *$ & $\begin{array}{l}0.093 \\
(1.87)\end{array}$ & $*$ & 208.46 & $* * *$ & 0.20 \\
\hline \multirow{7}{*}{ Call } & ARV9+J & $\begin{array}{l}-0.311 \\
(-5.72)\end{array}$ & $* * *$ & $\begin{array}{l}0.027 \\
(0.09)\end{array}$ & & $\begin{array}{l}0.398 \\
(8.05)\end{array}$ & $* * *$ & $\begin{array}{l}0.455 \\
(5.56)\end{array}$ & $* * *$ & $\begin{array}{l}0.081 \\
(1.11)\end{array}$ & & 256.57 & $* * *$ & 0.35 \\
\hline & ARV9+L & $\begin{array}{l}-0.326 \\
(-5.00)\end{array}$ & $* * *$ & $\begin{array}{l}-0.030 \\
(-0.02)\end{array}$ & & $\begin{array}{l}0.344 \\
(8.05)\end{array}$ & $* * *$ & $\begin{array}{l}0.450 \\
(5.01)\end{array}$ & $* * *$ & $\begin{array}{l}0.029 \\
(0.20)\end{array}$ & & 249.01 & $* * *$ & 0.28 \\
\hline & ARV9+J/L & $\begin{array}{l}-0.327 \\
(-5.01)\end{array}$ & $* * *$ & $\begin{array}{l}-0.031 \\
(-0.15)\end{array}$ & & $\begin{array}{l}0.351 \\
(8.05)\end{array}$ & $* * *$ & $\begin{array}{l}0.452 \\
(5.09)\end{array}$ & $* * *$ & $\begin{array}{l}0.072 \\
(0.95)\end{array}$ & & 250.27 & $* * *$ & 0.29 \\
\hline & ARRV30 & $\begin{array}{l}-0.195 \\
(-3.00)\end{array}$ & $* * *$ & $\begin{array}{l}0.001 \\
(0.18)\end{array}$ & & $\begin{array}{l}0.311 \\
(7.05)\end{array}$ & $* * *$ & $\begin{array}{l}0.370 \\
(5.25)\end{array}$ & $* * *$ & $\begin{array}{l}-0.055 \\
(1.00)\end{array}$ & & 201.12 & $* * *$ & 0.25 \\
\hline & ARV30+J & $\begin{array}{l}-0.187 \\
(-3.18)\end{array}$ & $* * *$ & $\begin{array}{l}0.015 \\
(0.12)\end{array}$ & & $\begin{array}{l}0.351 \\
(7.11)\end{array}$ & $* * *$ & $\begin{array}{l}0.364 \\
(5.10)\end{array}$ & $* * *$ & $\begin{array}{l}-0.060 \\
(1.94)\end{array}$ & $*$ & 216.77 & $* * *$ & 0.28 \\
\hline & ARV30+L & $\begin{array}{l}-0.192 \\
(-3.08)\end{array}$ & $* * *$ & $\begin{array}{l}-0.010 \\
(-0.21)\end{array}$ & & $\begin{array}{l}0.336 \\
(7.12)\end{array}$ & $* * *$ & $\begin{array}{l}0.350 \\
(4.98)\end{array}$ & $* * *$ & $\begin{array}{l}-0.050 \\
(2.03)\end{array}$ & $*$ & 200.14 & $* * *$ & 0.16 \\
\hline & ARV30+J/L & $\begin{array}{l}-0.191 \\
(-3.84)\end{array}$ & $* * *$ & $\begin{array}{l}-0.022 \\
(-0.29)\end{array}$ & & $\begin{array}{l}0.349 \\
(7.81)\end{array}$ & $* * *$ & $\begin{array}{l}0.310 \\
(4.55)\end{array}$ & $* * *$ & $\begin{array}{l}-0.057 \\
(-1.76)\end{array}$ & $*$ & 200.46 & $* * *$ & 0.20 \\
\hline \multirow{7}{*}{ Put } & ARV9+J & $\begin{array}{l}-0.314 \\
(-9.57)\end{array}$ & $* * *$ & $\begin{array}{l}-0.023 \\
(-3.56)\end{array}$ & $*$ & $\begin{array}{l}0.015 \\
(1.79)\end{array}$ & $*$ & $\begin{array}{l}0.602 \\
(10.69)\end{array}$ & $* * *$ & $\begin{array}{l}0.290 \\
(6.91)\end{array}$ & $* * *$ & 401.28 & $* * *$ & 0.45 \\
\hline & ARV9+L & $\begin{array}{l}-0.364 \\
(-9.91)\end{array}$ & $* * *$ & $\begin{array}{l}-0.022 \\
(-3.08)\end{array}$ & * & $\begin{array}{l}0.016 \\
(1.01)\end{array}$ & & $\begin{array}{l}0.695 \\
(10.34)\end{array}$ & $* * *$ & $\begin{array}{l}0.201 \\
(1.87)\end{array}$ & $*$ & 305.73 & $* * *$ & 0.40 \\
\hline & ARV9+J/L & $\begin{array}{l}-0.335 \\
(-9.00)\end{array}$ & $* * *$ & $\begin{array}{l}-0.029 \\
(-3.81)\end{array}$ & $*$ & $\begin{array}{l}0.011 \\
(1.50)\end{array}$ & & $\begin{array}{l}0.656 \\
(10.10)\end{array}$ & $* * *$ & $\begin{array}{l}0.274 \\
(5.89)\end{array}$ & $* * *$ & 361.61 & $* * *$ & 0.42 \\
\hline & ARRV30 & $\begin{array}{l}-0.385 \\
(-8.55)\end{array}$ & $* * *$ & $\begin{array}{l}-0.218 \\
(-2.05)\end{array}$ & $*$ & $\begin{array}{l}0.011 \\
(0.01)\end{array}$ & & $\begin{array}{l}0.754 \\
(13.18)\end{array}$ & $* * *$ & $\begin{array}{l}0.152 \\
(2.10)\end{array}$ & $* *$ & 280.13 & $* * *$ & 0.30 \\
\hline & $\mathrm{ARV} 30+\mathrm{J}$ & $\begin{array}{l}-0.302 \\
(-8.09)\end{array}$ & $* * *$ & $\begin{array}{l}-0.201 \\
(-1.04)\end{array}$ & & $\begin{array}{l}0.016 \\
(0.29)\end{array}$ & & $\begin{array}{l}0.700 \\
(13.18)\end{array}$ & $* * *$ & $\begin{array}{l}0.113 \\
(2.26)\end{array}$ & $* *$ & 291.07 & $* * *$ & 0.33 \\
\hline & ARV30+L & $\begin{array}{l}-0.345 \\
(-8.48)\end{array}$ & $* * *$ & $\begin{array}{l}-0.219 \\
(-1.49)\end{array}$ & & $\begin{array}{l}0.011 \\
(0.78)\end{array}$ & & $\begin{array}{l}0.810 \\
(13.18)\end{array}$ & $* * *$ & $\begin{array}{l}0.105 \\
(1.49)\end{array}$ & & 201.22 & $* * *$ & 0.28 \\
\hline & ARV30+J/L & $\begin{array}{l}-0.328 \\
(-8.66)\end{array}$ & $* * *$ & $\begin{array}{l}-0.203 \\
(-1.37)\end{array}$ & & $\begin{array}{l}0.012 \\
(0.54)\end{array}$ & & $\begin{array}{l}0.766 \\
(13.18)\end{array}$ & $* * *$ & $\begin{array}{l}0.110 \\
(2.06)\end{array}$ & $*$ & 205.87 & $* * *$ & 0.29 \\
\hline
\end{tabular}

Note: $* * *$, and $* * *$ indicate significance at the $10 \%, 5 \%$, and $1 \%$ levels, respectively. 
The encompassing regression model is specified as follows (IV-ARV model):

$$
\begin{aligned}
\operatorname{Ln}\left(\sigma_{t}^{\text {IV }}\right)= & \beta_{0}+\beta_{1} \operatorname{Ln}\left(\sigma_{t \mid \Omega}^{\text {TAIEX.HV }}\right)+\beta_{2} \operatorname{Ln}\left(\sigma_{t \mid \Omega_{t}}^{\text {TAIEX.ARV }}\right) \\
& +\beta_{3} \operatorname{Ln}\left(\sigma_{t \mid \Omega_{t-1}}^{\text {TX.HV }}\right)+\beta_{4} \operatorname{Ln}\left(\sigma_{t \mid \Omega_{t-1}}^{\text {TX.ARV }}\right)+\varepsilon_{t}
\end{aligned}
$$

where $\beta, \varepsilon$ and $\Omega_{\mathrm{t}-1}$ are the regression coefficients, error term, and information collected at time $\mathrm{t}-1$, respectively. $\sigma_{\mathrm{t}}^{\mathrm{IV}}$ is implied volatility. $\sigma_{t}^{\mathrm{TX}-\mathrm{HV}}$ and $\sigma_{\mathrm{t}}^{\mathrm{TX}-\mathrm{ARV}}$ are respectively historical volatility and realized volatility estimated by the ARFIMA model of TAIEX. $\sigma_{t}^{\mathrm{TX}-\mathrm{HV}}$ and $\sigma_{t}^{\mathrm{TX}-\mathrm{ARV}}$ are respectively historical volatility and realized volatility estimated by the ARFIMA model of TX. The superscript e stands for forecast value. RVs are estimated using the 9-minute interval and 30-minute interval. All options are with a maturity of 8 to 30 days.

Since some estimated RV explains IV poorly, we use the ARFIMA model to have better RV estimates (labeled as ARV) and use those RV estimates in running the encompassing regression as specified in Equation (3) (labeled as IV-ARV model). As Table 7 shows, ARV can explain IV much better. It is very noticeable that the spot ARV explains the call option IV quite well, as is true for futures ARV in forecasting the put option IV. Of the four volatility variables, futures HV is the best in explaining and forecasting power. The spot HV cannot forecast IV because it lacks the information contents provided by futures volatility. Overall, the RV estimated in the 9-minute interval via encompassing regression is superior to that estimated in the 30-minute interval. Results in Table 6 lead to similar conclusions. Furthermore, comparing the performance of different ARFIMA models in the 9-minute interval via encompassing regression analysis, we find that RV9 fitted with ARFIMA $+J$ model (ARV9+J) has high power of explanation for IV. This result implies that Taiwan stock market return does follow a jump path. ${ }^{8}$

\section{Summary}

The paper employs the volatility in the spot and futures markets in the encompassing regression model to forecast RV and IV respectively. Our study differs most from the literature in that we use asynchronous variables in the forecasting model. Moreover, these asynchronous predictors are all their forecasted values, rendering our forecasts much closer to the real world.

While RV can be non-stationary with high sample frequency (ABDL), a stationary RV also depends on trade-matching time. Our empirical evidence suggests that a stationary RV of TAIEX index is calculated from 6, 9, 15 and 30 minutes, which are all multiples of 45 seconds. Furthermore, the Bayesian estimates of the long-memory parameter confirm that the RVs of the TAIEX index possess long memory. Among all estimates of the long-memory

8 Results for forecasting errors and trading simulations have been omitted for space, yet available upon request. parameter, those from - RV9 and RV30 are more stationary.

While the prior literature contends that $\mathrm{HV}$ is less predictive of RV than IV, our results show that HV explains RV the best, owing mainly to the fact that we use HV forecasts from an ARMA model. Compared with the HV of futures, the HV of spot has more information content, which helps to explain RV. A relatively surprising finding is that DVF seems to have no information advantage over RV.

By using the volatility of spot and futures simultaneously in the encompassing regression model, the volatility of futures is significantly positively correlated with the forecast IV, suggesting that futures lead spot and that the underlying asset of the TXO is approximately TX instead of TAIEX. Given the non-tradability of TAIEX, option holders in Taiwan can only trade TX for hedging and arbitraging purposes, leading to better information content of the futures volatility. Nonetheless, the explanatory power of RV variable in the model is inferior to HV variable. But if we predict IV with ARV, the forecasting ability would enhance significantly through ARV of spot (for IV of calls) and ARV of futures (for IV of puts). The forecasting performance of the IV-ARV $+\mathrm{J}$ model in group RV9 is better, indicating the jump tendency in Taiwan stock returns.

Despite the fact that RV is less predictive of IV than ARV in the encompassing regression model, in simulated investments, the performances of the IV-RV model are superior to the IV-ARV $+\mathbf{J}$ model in the pre-Presidential election period. When we consider transaction costs, rate of return in most models becomes negative. Yet, the returns from the IV-ARV+J model remain positive and the highest, showing that the IV-ARV $+\mathrm{J}$ model approaches the real world more closely.

\section{References}

[1] Aït-Sahalia, Y., P. A. Mykland, and L. Zhang, 2005, "How often to sample a continuous-time process in the presence of market microstructure noise." Review of Financial Studies 18, 351-416.

[2] Andersen, T. G., and T. Bollerslev, 1997, "Intraday periodicity and volatility persistence in financial markets." Journal of Empirical Finance 4, 115-158.

[3] Andersen, T. G., T. Bollerslev, and F. X. Diebold, 2007, "Roughing it up: Disentangling continuous and Jump components in measuring, modeling and forecasting asset return volatility." Review of Economics and Statistics, 89, 701-720.

[4] Andersen, T. G., T. Bollerslev, F. X. Diebold, and P. Labys, 2001, "The distribution of realized exchange rate volatility." Journal of the American Statistical Association 96, 42-55.

[5] Andersen, T. G., T. Bollerslev, F. X. Diebold, and P. Labys, 2003, "Modeling and forecasting realized volatility." Econometrica, 71, 579-625.

[6] Andersen, T., T. Bollerslev, F. Diebold, and H. Ebens, 2001, The distribution of realized stock return volatility. Journal of Financial Economics, 61, 43-76. 
[7] Asai, M., R. Gupta, and M. McAleer, 2020, "Forecasting volatility and co-volatility of crude oil and gold futures: Effects of leverage, jumps, spillovers, and geopolitical risks." International Journal of Forecasting 36, 933-948.

[8] Bakshi, G., C. Cao, and Z. Chen, 1997, "Empirical performance of alternative option pricing models." Journal of Finance 52, 2003-2049.

[9] Black, F., 1976, "The pricing of commodity contracts." Journal of Financial Economics 3, 167-179.

[10] Black, F., and M. Scholes, 1973, "The pricing of options and corporate liabilities." Journal of Political Economy 81, 637-659.

[11] Blair, B. J., S. Poon, and S. J. Taylor, 2001, "Forecasting S\&P 100 volatility: The incremental information content of implied volatilities and high-frequency index returns." Journal of Econometrics 105, 5-26.

[12] Campa, J. M. and P. H. K. Chang, 1998, "The forecasting ability of correlations implied in foreign exchange options." Journal of International Money and Finance 17, 855-880.

[13] Canina, L., and S. Figlewski, 1993, "The informational content of implied volatility.” Review of Financial Studies 6, 659-681.

[14] Chan, K., 1992, "A further analysis of the lead-lag relationship between the cash market and stock index futures market." Review of Financial Studies 5, 23-152.

[15] Chan, W. H., R. Jha, and M. Kalimipalli, 2009, "The economic value of using realized volatility in forecasting future implied volatility." Journal of Financial Research 32, 231-259.

[16] Chiras, D. P., and S. Manaster, 1978, "The information content of option prices and a test of market efficiency." Journal of Financial Economics 10, 213-234.

[17] Christie, A. A., 1982, "The stochastic behavior of common stock variances: Value, leverage and interest rate effects." Journal of Financial Economics 10, 407-432.

[18] Cheung, Y., and L. Ng, 1992, "Stock Price Dynamics and Firm Size: An Empirical Investigation." Journal of Finance 47, 1985-1997.

[19] Christensen, B. J., and N. R. Prabhala, 1998, "The relation between implied and realized volatility." Journal of Financial Economics 50, 125-150.

[20] Clemen, R. T., 1989, "Combining forecasts: A review and an annotated bibliography." International Journal of Forecasting $5,559-583$.

[21] Dumas, B., J. Fleming, and R. E. Whaley, 1998, "Implied volatility functions: Empirical tests." Journal of Finance 53, 2059-2106

[22] Fair, R. C., and R. J. Shiller, 1990, "Comparing information in forecasts from econometric models." American Economic Review 80, 375-389.

[23] Fleming, J., 1998, "The quality of market volatility forecasts implied by S\&P 100 index option prices." Journal of Empirical Finance 5, 317-345.

[24] Fleming, J., B. Ostdiek, and R. E. Whaley, 1996, "Trading costs and the relative rate of price discovery in stock, futures, and options markets." Journal of Futures Markets 16, 353-387.
[25] Gemmill, G., 1986, "The forecasting performance of stock options on the London traded options marker." Journal of Business Finance and Accounting 13, 535-546.

[26] Geweke, J., and S. Porter-Hudak, 1983, "The estimation and application of long memory time series models." Journal of Time Series Analysis 4, 221-238.

[27] Granger, C. W. J., 1980, "Long memory relationships and the aggregation of dynamic models." Journal of Econometrics 14, 227-238.

[28] Granger, C. W. J., and R. Joyeux, 1980, "An introduction to long-memory time series models and fractional differencing." Journal of Time Series Analysis 1, 15-30.

[29] Hsieh, G., 2002, "Market integration, price discovery, and information transmission in Taiwan index futures market." Journal of Financial Studies 10, 1-31.

[30] Hosking, J. R. M., 1981, "Fractional differencing." Biometrika 68, 165-176.

[31] Janacek, G., 1982, "Determining the degree of differencing for time series via the long spectrum." Journal of Time Series Analysis 3, 177-183.

[32] Jang, W. Y., and Y. F. He, 2004, "The temporal price relationships between spot, futures and options values on the TSE: early evidence." Journal of Emerging Markets 9, 10-21.

[33] Jiang, G. J., and Y. S. Tian, 2005, "The Model-Free implied volatility and its information content." Review of Financial Studies 18, 1305-1342.

[34] Jorion, P., 1995, "Predicting volatility in the foreign exchange market." Journal of Finance 50, 507-528.

[35] Kawaller, I. G., P. D. Koch, and T. W. Koch, 1987, “The temporal price relationship between S\&P 500 futures and the S\&P 500 index.” Journal of Finance 42, 1309-1329.

[36] Koop, G., E. Ley, J. Osiewalski, and M. F. J. Steel, 1997, "Bayesian analysis of long memory and persistence using ARFIMA models." Journal of Econometrics 76, 149-169.

[37] Koopman, S. J., B. Jungbacker, and U. E. Hol, 2005, "Forecasting daily variability of the S\&P 100 stock index using historical, realized and implied volatility measurements." Structural Breaks and Nonlinearity. Tinbergen Institute Discussion Paper.

[38] Lamoureux, C. G., and W. D. Lastrapes, 1993, "Forecasting stock-return variance: Toward an understanding of stochastic implied volatilities." Review of Financial Studies 6, 293-326.

[39] Lin, C. C., S. Y. Chen, D. Y. Hwang, and C. F. Lin, 2002, "Does index futures dominate index spot? Evidence from Taiwan market." Review of Pacific Basin Financial Markets and Policies 5, 255 - 275.

[40] Ma, F., Y. Wei, L. Liu, and D. Huang, 2018, "Forecasting realized volatility of oil futures market: A new insight." Journal of Forecasting 37, 419-436.

[41] Mayhew, S., 1995, "Implied volatility." Financial Analysts Journal 51, 8-20.

[42] Mincer, J., and V. Zarnowitz, 1969, "The evaluation of economic forecasts" in J. Mincer, ed., 'Economic Forecasts and Expectations', NBER, New York. 
[43] Neely, C. J., 2009, "Forecasting foreign exchange volatility: Why is implied volatility biased and inefficient? And does it matter?" Journal of International Financial Markets, Institutions and Money 19, 188-205.

[44] Parkinson, M., 1980, "The Extreme value method for estimating the variance of the rate of return." Journal of Business 53, 61-65.

[45] Poon, S., and C. W. J. Granger, 2003, "Forecasting volatility in financial markets: A review." Journal of Economic Literature 41, 478-539.

[46] Pong, S., M. B. Shackleton, S. J. Taylor, and X. Xu, 2004, "Forecasting currency volatility: A comparison of implied volatilities and AR(FI)MA Models." Journal of Banking and Finance 28, 2541-2563.
[47] Rubinstein, M., 1994, "Implied Binomial Trees." Journal of Finance 49, 771-818

[48] Schwert, G. W., and P. J. Seguin, 1990, "Heteroskedasticity in stock returns.” Journal of Finance 45, 1129-1155.

[49] Stoll, H. R., and R. E. Whaley, 1990, "The dynamics of stock index and stock index futures returns." Journal of Financial and Quantitative Analysis 25, 441-468.

[50] Tan, S., K. Ng, J. Chan, and I. Mohamed, 2019, "Quantile range-based volatility measure for modelling and forecasting volatility using high frequency data." North American Journal of Economics and Finance 47, 537-551.

[51] Whaley, R. E., 1982, "Valuation of American call options on dividend-paying stocks." Journal of Financial Economics 10, 29-58. 